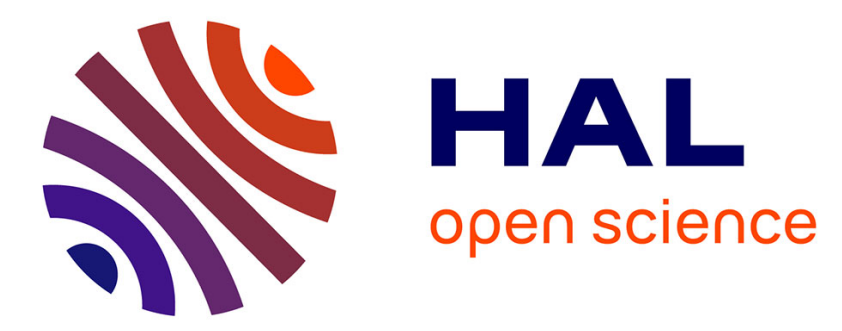

\title{
Knowledge and its Game-Theoretical Foundations: The Challenges of the Dialogical Approach to Constructive Type Theory
}

Shahid Rahman, Radmila Jovanovic, Nicolas Clerbout

\section{- To cite this version:}

Shahid Rahman, Radmila Jovanovic, Nicolas Clerbout. Knowledge and its Game-Theoretical Foundations: The Challenges of the Dialogical Approach to Constructive Type Theory. Epistemology, Knowledge and the Impact of Interaction, Springer, 2016. halshs-01227833

\section{HAL Id: halshs-01227833 \\ https://shs.hal.science/halshs-01227833}

Submitted on 12 Nov 2015

HAL is a multi-disciplinary open access archive for the deposit and dissemination of scientific research documents, whether they are published or not. The documents may come from teaching and research institutions in France or abroad, or from public or private research centers.
L'archive ouverte pluridisciplinaire HAL, est destinée au dépôt et à la diffusion de documents scientifiques de niveau recherche, publiés ou non, émanant des établissements d'enseignement et de recherche français ou étrangers, des laboratoires publics ou privés. 


\title{
Knowledge and its Game-Theoretical Foundations: The Challenges of the Dialogical Approach to Constructive Type Theory
}

\author{
Shahid Rahman*, Radmila Jovanovic**, Nicolas Clerbout*** \\ *Université de Lille, UMR 8163: STL ${ }^{1}$, **University of Belgrade; ***CDHACS- \\ Universidad de Valparaíso \\ (Draft, 26 March 2015)
}

\begin{abstract}
It is our main claim that the time is ripe to link the dynamic turn launched by game-theoretical approaches to meaning with P. Martin-Löf's Constructive Type Theory (CTT). Furthermore, we also claim that the dialogical framework provides the appropriate means to develop such a link. We will restrict our study to the discussion of two paradigmatic cases of dependences triggered by quantifiers, namely the case of the Axiom of Choice and the study of anaphora, that are by the way two of the most cherished examples of Hintikka.
\end{abstract}

Keywords: knowledge, constructive type theory, epistemic logic, dialogical logic, game-theoretical semantics,

\section{Introduction}

Since the emergence of logic as a scientific discipline in the ancient tradition the interface between knowledge, reasoning and logic grew up as constituting a tight braid that structured the dynamics of public and scientific debates and more generally of rational argumentative interaction and decision making. However, around the dawn of the $\mathrm{XX}^{\text {th }}$ century, the braid loosened and fell apart into separate threads. In fact, it is during the years that followed immediately after the failure of the logical positivism project that the links between science as a body of knowledge and the study of the process by which knowledge is achieved and grounded were cut off. ${ }^{2}$

Nevertheless, around 1960 epistemic approaches that echoed the old traditions, challenged the mainstream current that followed from the work of A. Tarski, K. Gödel and P. Bernays. ${ }^{3}$ Those epistemic approaches, which, a while later, were called, following Michael Dummett, antirealists, found their formal argument in the mathematics of Brouwer and intuitionistic logic, while the others persisted with the formal background of the Tarski tradition, where Cantorian set theory is linked via model theory to classical logic. The point is that while for intuitionists the notion of proposition is based on a theory of meaning where knowledge plays a crucial role and where acquisition of such knowledge is expressed by a judgement, the model-theoretic tradition took truth rather than knowing the truth as their foundations of formal semantics. Intuitionists, as pointed out by D. Prawitz (2012, p. 47) avoid the term truth and reject the idea that intuitionism could replace " $p$ is true" with "there exists a proof of $p$ " understood in a realistic vein. Indeed, the existence of a proof, as pointed out by Prawitz in the same text, is to be understood epistemically as the actual experience of the construction intended by the

\footnotetext{
${ }^{1}$ The present paper is part of an ongoing project in the context of the research-program "Argumentation, Decision, Action" (ADA) and the project LACTO both supported by the Maison Européenne des Sciences de l'Homme et de la Société - USR 318 and by the laboratory UMR 8163: STL.

${ }^{2}$ Cf. Sundholm (1998 and 2009).

${ }^{3}$ Cf. Rahman/Primiero/Marion (2012, pp. vii-ix).
} 
proposition, not as the existence of an ontological fact. More generally, from the intuitionistic point of view proof-theory provides the means for the development of an epistemic approach to meaning rooted in assertions (rather than propositions). In this context, it should be mentioned that already in 1955 Paul Lorenzen proposed an operative approach that delved into the conceptual and technical bonds between procedure and knowledge. ${ }^{4}$ The insights of Lorenzen's Operative Logik, as pointed out by Schröder-Heister (2008), had lasting consequences in the literature on proof-theory and still deserve attention nowadays. Indeed, the proof-theoretical notion of harmony formulated by the logicians that favoured the epistemic approach such as Dag Prawitz ${ }^{5}$ has been influenced by Lorenzen's notions of admissibility, eliminability and inversion. ${ }^{6}$

However, the epistemic perspectives did not all reduce to the proof-theoretical framework: epistemic features were also implemented via game-theoretical approaches. Indeed, on one hand, by the 1960s appeared Dialogical logic developed by Paul Lorenzen and Kuno Lorenz, as a solution to some of the problems that arouse in Lorenzen's Operative Logik. ${ }^{7}$ Herewith, the epistemic turn initiated by the proof theoretic was tackled with the notion of games that provided the dynamic features of the traditional dialectical reasoning. Inspired by Wittgenstein's meaning as use the basic idea of the dialogical approach to logic is that the meaning of the logical constants is given by the norms or rules for their use. On the other hand, a bit later on, still in the sixties, Jaakko Hintikka developed game-theoretical semantic (GTS). GTS is an approach to formal semantics that, like in the dialogical framework, grounds the concepts of truth or validity on game-theoretical concepts, such as the existence of a winning strategy for a player, though differently to the dialogical framework it is build up on the notion of model. ${ }^{8}$ Furthermore, Hintikka combined the model-theoretical, the epistemic and the game-based traditions by means of the development of what is now known as explicit epistemic logic, where the epistemic content is introduced into the object language as an operator (of some specific modal kind) which yields propositions from propositions rather than as meaning conditions on the notion of proposition and inference. These kinds of operators were rapidly generalized covering several propositional attitudes including notably knowledge and belief.

These new impulses experienced, by 1980 a parallel renewal in the fields of theoretical computer science, computational linguistics, artificial intelligence and the formal semantics of programming languages. The impulse was triggered by the work of Johan van Benthem ${ }^{9}$ and collaborators in Amsterdam who not only looked thoroughly at the interface between logic and games but also provided new and powerful tools to tackle the issue of the expressivity of a language - in particular the capability of propositional

\footnotetext{
${ }^{4}$ Lorenzen (1955).

${ }^{5}$ Prawitz (1979). For recent discussions related to the topic of harmony, see Read $(2008,2010)$.

${ }^{6} \mathrm{Cf}$. Schröder-Heister (2008).

${ }^{7}$ The main original papers are collected in Lorenzen/Lorenz (1978). For an historical overview of the transition from operative logic to dialogical logic see Lorenz (2001). For a presentation about the initial role of the framework as a foundation for intuitionistic logic, see Felscher (1994). Other papers have been collected more recently in Lorenz (2010a,b).

${ }^{8}$ Hintikka (1962, 1973, 1996a), Hintikka/Sandu (1997). See also Hintikka (1999) and in particular Hintikka et al. (1999). Shahid Rahman and Tero Tulenheimo (2009) studied the relation between dialogical logic and GTS.

${ }^{9}$ van Benthem $(1996,2011,2014)$.
} 
modal logic to express some decidable fragments of first-order logic. ${ }^{10} \mathrm{New}$ results in linear logic by J-Y. Girard in the interfaces between mathematical game theory and proof theory on one hand and argumentation theory and logic on the other hand resulted in the work of many others, including S. Abramsky, J. van Benthem, A. Blass, H. van Ditmarsch, D. Gabbay, M. Hyland, W. Hodges, R. Jagadessan, G. Japaridze, E. Krabbe, L. Ong, H. Prakken, G. Sandu D. Walton, and J. Woods who placed game semantics in the center of new concept of logic in which logic is understood as a dynamic instrument of inference. ${ }^{11}$. A dynamic turn, as van Benthem puts it, is taking place and K. Lorenz's work on dialogical logic is a landmark in this turn. In fact, Lorenz's work can be more accurately described as the dialogical turn that re-established the link between dialectical reasoning and inference interaction. ${ }^{12}$

Now, most of the logicians who endorse the dynamic turn ${ }^{13}$ seem to ignore a recent study that represents a major advance in the task of recovering the logic of knowledge, namely, the development by Per Martin-Löf of the logical foundations of constructive mathematics that yielded Constructive Type Theory (CTT). This theory that provides a type theoretical development of the Curry-Howard-Isomorphism between, propositions as programs and propositions as sets-types, by introduction dependent types leads to the formulation of a fully-interpreted language - a language with content that challenges the usual metalogical approach to meaning of standard modal theoretic semantics. ${ }^{14}$ In the CTT-framework the distinction between the classical (and realist) and constructivist positions can be expressed by distinguishing between assertion, the content of an assertion and the proposition expressed by an assertion in the following way: A proposition is classically determined by its truth-condition and constructively by its proof-objects; the content of an assertion amounts, according to the classical perspective, to the (transcendent) satisfaction of the truth-condition while constructively it amounts to the existence of a proof-object, and finally for both, classical and constructivists, an

${ }^{10}$ van Benthem (2001).

${ }^{11}$ See also: Blass (1992), Abramsky/Mellies (1999), Girard (1999), Lecomte/Quatrini(2010,2011), Lecomte (2011) and Lecomte/Tronçon (2011).

${ }^{12}$ This link provides the basis of a host of current and ongoing works in the history and philosophy of logic, going from the Indian, the Chinese, the Greek, the Arabic, the Hebraic traditions, the Obligationes of the Middle Ages to the most contemporary developments in the study of epistemic interaction. The main original papers on the dialogical approach are collected in Lorenzen/Lorenz (1978). For an historical overview see Lorenz (2001). For a presentation about the initial role of the framework as a foundation for intuitionistic logic, see Felscher (1985). Other papers have been collected more recently in Lorenz (2008, 2010a,b). A detailed account of recent developments since, say, Rahman (1993), can be found in Rahman/Keiff (2005) and Keiff (2009). For the underlying metalogic see Clerbout (2014a,b). For a textbook presentation: Redmond/Fontaine (2011) and Rückert (2011a). For the key role of dialogic in regaining the link between dia lectics and logic, see Rahman/Keff (2010). Keiff (2004a,b) and Rahman (2009) study Modal Dialogical Logic. Fiutek et al. (2010) study the dialogical approach to belief revision. Clerbout/Gorisse/Rahman (2011) studied Jain Logic in the dialogical framework. Popek (2012) develops a dialogical reconstruction of medieval obligationes. For other books see Redmond (2010) - on fiction and dialogic - Fontaine (2013) - on intentionality, fiction and dialogues - and Magnier (2013) - on dynamic epistemic logic van Ditmarsch et al. (2007) and legal reasoning in a dialogical framework.

${ }^{13}$ With the remarkable exceptions of of J.-Y. Girard and A. Ranta.

${ }^{14}$ Indeed, constructive-type-theoretical grammar Ranta (1994), Ginzburg (2012) has now been successfully applied to the foundations of mathematics, logic, philosophy of logic, computer sciences, and to the semantics of natural languages. Particularly interesting is the fact that Ginzburg deploys CTT in order to capture the meaning of interaction underlying conversations in natural language. 
assertion indicates that the fact (=: truth-condition/proof-object) expressed by its content is known.

From the point of view of the modal approaches to epistemic logic in the Hintikka-style as developed for example by the school of J. Van Benthem at Amsterdam, the lack of interest in CTT is not a surprise, after all their game-theoretical approach is based on a model theoretic semantics, where meaning is explained by metalinguistic means that relate uninterpreted signs and world. However, the, up to now, missing interface between the dialogical framework and CTT is particularly striking because of the common philosophical grounds of dialogical logic and those of constructive logic, where, as mentioned above, meaning of a linguistic expression is conceived as being constituted by the norms or rules for its use. Indeed, if the use-approach to meaning is intended to implement in logic Wittgenstein's notion of language-games, who rejected the metalogical approach of model-theoretic semantics, the links between CTT and dialogical logic, seem to be very natural. More generally, if, once more, meaning is related to actions and those actions are understood as deploying games of answers and questions that involve the meaning of one main sentence, the game-theoretical approach to CTT follows naturally. One possible way to put it is to follow Mathieu Marion's ${ }^{15}$ proposal and to make use of Robert Brandom's $(1994,2000)$ pragmatist take on inferentialism, which is led by two main insights of Kantian origin and one that stems from Brandom's reading of Hegel

1) That judgements are the fundamental units of knowledge, and

2) That human cognition and action is characterized by certain sorts of normative assessment. ${ }^{16}$

3) Communication is mainly conceived as cooperation in a joint social activity rather than on sharing contents. ${ }^{17}$

The crucial point of the epistemic approach, as mentioned above, is that assertion or judgement amounts to a knowledge claim and this is independent of classical or intuitionistic views cf. Prawitz (2012, p. 47). So, if meaning of an expression is deployed from its role in assertions, then an epistemic approach to meaning results. In relation to the second point, according to Brandom, the normative aspect is implemented via W. Sellar's notion of games of giving and asking for reasons, which deploy the intertwining

${ }^{15}$ In fact, Mathieu Marion $(2006,2009,2010)$ was the first to propose a link between Brandom's pragmatist inferentialism and dialogical logic in the context of Wilfried Hodges (2001, 2004(rev.2013) challenges to the games theoretical approaches. Moreover, another relevant antecedent of the present work is the PHDthesis of Laurent Keiff (2007) who provided a thorough formulation of dialogical logic within the framework of speech-act theory.

${ }^{16}$ The normative aspect, rooted on the shift from Cartesian certainty to bindingness of rules distinguishes Brandom's pragmatism of others:

One of the strategies that guided this work is a commitment to the fruitfulness of shifting theoretical attention from the Cartesian concern with the grip we have on concepts - for Descartes, in the particular form of the centrality of the notion of certainty [...] - to the Kantian concern with the grip concepts have on us, that is the notion of necessity as the bindingness of the rules (including inferential ones) that determine how it is correct to apply those concepts (Brandom 1994, p. 636).

${ }^{17}$ In relation to the model of holistic communication envisaged Brandom 1994, p. 479) writes:

Holism about inferential significances has different theoretical consequences depending on whether one thinks of communication in terms of sharing a relation to one and the same thing (grasping a common meaning) or in terms of cooperating in a joint activity [...]. 
of commitments and entitlements. Indeed, on Brandom's view, it is the chain of commitments and entitlements in a game of giving and asking for reasons that tights up judgement and inference. ${ }^{18}$ Göran Sundholm (2013b) provides the following formulation of the notion of inference in a communicative context that can be also seen as the describing the core of Brandom's pragmatist inferentialism:

\section{When I say "Therefore" I give others my authority for asserting the conclusion, given theirs for asserting the premsisses. ${ }^{19}$}

This is quite close to the main tenet of the dialogical approach to meaning with one important and crucial difference: though the pragmatist approach to meaning of the dialogical framework shares with Brandom's pragmatist inferentialism the claim that the meaning of linguistic expressions is related to their role in games of questions and answers and also endorses Brandom's notion of justification of a judgement as involving the interaction of commitments and entitlements, dialogicians maintain that more fundamental lower-levels should be distinguished. Those lower-level semantic levels include (i) the description of how to formulate a suitable question to give a posit and how to answer it, and (ii) the development of plays, constituted by several combinations of sequences of questions and answers brought forward as responses to the posit of a thesis. From the dialogical perspective, the level of judgements corresponds to the final stage of the chain of interactions just mentioned. More precisely, the justifications of judgements correspond to the level of winning strategies, that select those plays that turn out to be relevant for the drawing of inferences. Furthermore, as our discussion of the Axiom of Choice shows, the game-theoretical take on the dependent types is rooted on choices dependences, that can be seen as a result of the intertwining of games of questions and answers.

Let us point out that the distinctions: local meaning, play level and strategy level, drawn within the dialogical framework, seem to provide an answer to Brandom's question involving his claim that the "grasp of concepts" amounts to the mastery of inferential roles but this

[...] does not mean that in order to count as grasping a particular concept an individual must be disposed to make or otherwise endorse in practice all the right inferences involving it. To be in the game at all, one must make enough of the right moves - but how much is enough is quite flexible. Brandom (1994, p. 636).

Indeed, from the dialogical point of view, in order to grasp the meaning of an expression, the individual must not need to know the moves that lead on how to win, he must not have a winning strategy, what it is required is that the knows what are the relevant moves he is entitled and committed to (local meaning) in order to develop a play

\footnotetext{
${ }^{18}$ Moreover, according to Brandom, games of asking for reasons and giving them constitute the base of any linguistic practice:

Sentences are expressions whose unembedded utterance performs a speech act such as making a claim, asking a question, or giving a command. Without expressions of this category; there can be no speech acts of any kind, and hence no specifically linguistic practice (Brandom 2000, p. 125).

${ }^{19}$ Actually, Sundholm bases his formulation on J. L. Austin remarks in the celebrated paper of 1946, Other Minds rather than on Brandom's work.
} 
- in a similar way to knowing how to play chess does not necessarily mean to actually be in possession of a winning strategy. Knowing how to play allows to know what can count as a winning strategy, when there is one: strategic legitimacy (Geltung) is not to be found at the level of meaning-explanation. Thus, one way to see the motivations that animates the proposal to link CTT and games is to furnish the technical elements that bind the pragmatist approach to the grasp of concepts in Brandom's style, with the prooftheoretical CTT take on meaning.

The issue is now on how to link precisely the dynamic and epistemic turn with the fully-interpreted-approach of CTT in such a way that

a) it incorporates the game-theoretical interpretation, where different kind of dependences are understood as deploying specific forms of interaction

b) it makes it possible to express both the dynamics of knowledge acquisition and of meaning formation at the object language level.

It is our main claim that this can be achieved by the recent dialogical approach to CTT, where a language with content is developed that is able to meet the challenges of a framework where meaning and knowledge are conceived as constituted within interaction. ${ }^{20}$ We will discuss two main cases, that represent two of the most cherished examples of Hintikka, namely the case of the Axiom of Choice and the study of anaphora (also one of Brandom's favourite subjects of study). To say it straight away, our claim is that the targets expressed by a) and b) can be achieved if we adopt the point of view that those functions that Hintikka identified as the ones that provide meaning to quantifier dependences are in fact object language proof-objects of the propositions in which the quantifiers occur, more precisely this functions are nothing more than dependent proofobjects. Moreover, proof-objects are made of more elementary constituents that we call play-objects. However all this considerations seem to point out, that at the end Hintikka's claim of super-classicality is not compatible with a theory of meaning that makes interaction explicit at the object language level.

\section{The Dialogical Approach to CTT $^{21}$}

\section{1 Dialogical Logic and the Pragmatist Theory of Meaning}

The dialogical approach to logic is not a specific logical system but rather a rule-based semantic framework in which different logics can be developed, combined and compared. An important point is that the rules that fix meaning can be of more than one kind. This feature of its underlying semantics quite often motivated the dialogical framework to be understood as a pragmatist semantics. More precisely, in a dialogue two parties argue about a thesis respecting certain fixed rules. The player that states the thesis is called Proponent (P), his rival, who contests the thesis is called Opponent $(\mathbf{O})$. In its original

${ }^{20}$ Cf. Rahman/Clerbout (2013, 2015), Clerbout/Rahman (2015), Jovanovic (2014).

${ }^{21}$ The present overview on the dialogical approach to CTT is based on Clerbout/Rahman (2015) - see also

Rahman/Clerbout (2013, 2015), Rahman/Clerbout/McConaughey (2014). 
form, dialogues were designed in such a way that each of the plays end after a finite number of moves with one player winning, while the other loses. Actions or moves in a dialogue are often understood as speech-acts involving declarative utterances or posits and interrogative utterances or requests. The point is that the rules of the dialogue do not operate on expressions or sentences isolated from the act of uttering them. The rules are divided into particle rules or rules for logical constants (Partikelregeln) and structural rules (Rahmenregeln). The structural rules determine the general course of a dialogue game, whereas the particle rules regulate those moves (or utterances) that are requests and those moves that are answers (to the requests). ${ }^{22}$

Crucial for the dialogical approach are the following points: ${ }^{23}$

1. The distinction between local (rules for logical constants) and global meaning (included in the structural rules that determine how to play)

2. The player independence of local meaning

3. The distinction between the play level (local winning or winning of a play) and the strategic level (existence of a winning strategy).

4. A notion of validity that amounts to winning strategy independently of any model instead of winning strategy for every model.

5. The distinction between non formal and formal plays - neither latter nor the first kind concerns plays where the actions of positing an elementary sentences require a meta-language level that provides their truth.

Recent developments in dialogical logic show that the CTT approach to meaning is very natural to game-theoretical approaches where (standard) metalogical features are explicitly displayed at the object language-level. ${ }^{24}$ Thus, in some way, this vindicates, albeit in quite of a different manner, Hintikka's plea for the fruitfulness of gametheoretical semantics in the context of epistemic approaches to logic, semantics and the foundations of mathematics. In fact, from the dialogical point of view, those actions that constitute the meaning of logical constants, such as choices, are a crucial element of its full-fledged (local) semantics. Indeed, if meaning is conceived as being constituted during interaction, then all of the actions involved in the constitution of the meaning of an expression should be rendered explicit. They should all be part of the object language. The roots of this perspective are based on Wittgenstein's Unhintergehbarkeit der Sprache - one of the tenets of Wittgenstein that Hintikka explicitly rejects. ${ }^{25}$ According to this perspective of Wittgenstein language-games are purported to accomplish the task of displaying this "internalist feature of meaning". Furthermore, one of the main insights of Kuno Lorenz' interpretation of the relation between the so-called first and second Wittgenstein is based on a thorough criticism of the metalogical approach to meaning Lorenz (1970, pp. 74-79). ${ }^{26}$

${ }^{22}$ For a brief presentation of standard dialogical logic see appendix.

${ }^{23}$ Cf. Rahman (2012).

${ }^{24}$ Cf. Rahman/Clerbout (2013, 2015), Clerbout/Rahman (2015).

${ }^{25}$ Hintikka shares this rejection with all those who endorse model-theoretical approaches to meaning.

${ }^{26}$ In this context Lorenz writes : Also propositions of the metalanguage require the understanding of propositions, [...] and thus can not in a sensible way have this same understanding as their proper object. The thesis that a property of a propositional sentence must always be internal, therefore 
If we recall Hintikka's (1996b) extension of van Heijenoort distinction of a language as the universal medium and language as a calculus, the point is that the dialogical approach shares some tenets of both conceptions. Indeed, on one hand the dialogical approach shares with universalists the view that we cannot place ourselves outside our language, on the other it shares with the anti-universalists the view that we can develop a methodical of local truth.

Similar criticism to the metalogical approach to meaning has been raised by $\mathrm{G}$. Sundholm $(1997,2001)$ who points out that the standard model-theoretical semantic turns semantics into a meta-mathematical formal object where syntax is linked to meaning by the assignation of truth values to uninterpreted strings of signs (formulae). Language does not any more express content but it is rather conceived as a system of signs that speaks about the world - provided a suitable metalogical link between signs and world has been fixed. Moreover, Sundholm (2013a) shows that the cases of quantifier-dependences that motivate Hintikka's IF-logic can be rendered in the frame of CTT. What we add to Sundholm's remark is that even the game-theoretical interpretation of these dependences can be given a CTT formulation, provided this is developed within a dialogical framework.

In fact, in his 1988 paper, Ranta linked for the first time game-theoretical approaches with CTT. Ranta took Hintikka's Game-Theoretical Semantics as a case study, though his point does not depend on that particular framework: in game-based approaches, a proposition is a set of winning strategies for the player positing the proposition. ${ }^{27}$ In game-based approaches, the notion of truth is at the level of such winning strategies. Ranta's idea should therefore let us safely and directly apply to instances of game-based approaches methods taken from constructive type theory.

But from the perspective of game-theoretical approaches, reducing a game to a set of winning strategies is quite unsatisfactory, especially when it comes to a theory of meaning. This is particularly clear in the dialogical approach in which different levels of meaning are carefully distinguished. There is thus the level of strategies which is a level of meaning analysis, but there is also a level prior to it which is usually called the level of plays. The role of the latter level for developing an analysis is crucial according to the dialogical approach, as pointed out by Kuno Lorenz in his 2001 paper:

\section{[...] for an entity [A] to be a proposition there must exist a dialogue game associated with this entity [...] such that an individual play of}

amounts to articulating the insight that in propositions about a propositional sentence this same propositional sentence does not express anymore a meaningful proposition, since in this case it is not the propositional sentence that it is asserted but something about it.

Thus, if the original assertion (i.e., the proposition of the ground-level) should not be abrogated, then this same proposition should not be the object of a metaproposition, [...]. (Lorenz 1970, p.75).

While originally the semantics developed by the picture theory of language aimed at determining unambiguously the rules of "logical syntax" (i.e. the logical form of linguistic expressions) and thus to justify them [...] - now language use itself, without the mediation of theoretic constructions, merely via "language games", should be sufficient to introduce the talk about "meanings" in such a way that they supplement the syntactic rules for the use of ordinary language expressions (superficial grammar) with semantic rules that capture the understanding of these expressions (deep grammar). (Lorenz 1970, p.109).

${ }^{27}$ That player can be called Player 1, Myself or Proponent. 
the game where A occupies the initial position [...] reaches a final

position with either win or loss after a finite number of moves [...]

For this reason we would rather have propositions interpreted as sets of what we shall call play-objects and read the expression

$$
p: \varphi
$$

as " $p$ is a play-object for $\varphi$ ".

Thus, Ranta's work on proof-objects and strategies is the end, not the beginning, of the dialogical project.

\section{2 The Formation of Propositions}

Before delving into the details about play-objects, let us first discuss the issue of forming expressions and especially propositions in the dialogical approach.

It is presupposed in standard dialogical systems that the players use well-formed formulas (wff). The well formation can be checked at will, but only with the usual meta reasoning by which the formula is checked to indeed observe the definition of a wff. We want to enrich the system by first allowing players to enquire on the status of expressions and in particular to ask if a certain expression is a proposition. We thus start with dialogical rules explaining the formation of propositions. These rules are local rules which we are added to the particle rules giving the local meaning of logical constants (see next section).

A remark before displaying the formation rules: because the dialogical theory of meaning is based on argumentative interaction, dialogues feature expressions which are not only posits of sentences. They also feature requests, used for challenges, as the formation rules below and the particle rules in the next section illustrate. Because of the no entity without type principle, it seems at first glance that we should specify the type of these actions during a dialogue: the type "formation-request". It turns out we should not: an expression such as " ${ }_{F}$ : formation-request" is a judgement that some action $?_{F}$ is a formation-request, which should not be confused with the actual act of requesting. We also consider that the force symbol $?_{F}$ makes the type explicit. Hence the way requests are written in rules and dialogues in this work.

The formation rules are given in following table. Notice that a posit ' $\perp$ : prop' cannot be challenged: this is the dialogical account of the fact that the falsum $\perp$ is by definition a proposition. 


\begin{tabular}{|c|c|c|}
\hline Posit & $\begin{array}{l}\text { Challenge } \\
\text { [when different challenges are } \\
\text { possible, the challenger } \\
\text { chooses] }\end{array}$ & Defence \\
\hline $\mathbf{X} ! \Gamma:$ set & $\begin{array}{l}\mathbf{Y} ?_{\operatorname{can}} \Gamma \\
\text { or } \\
\mathbf{Y} ?_{\mathrm{gen}} \Gamma \\
\text { or } \\
\mathbf{Y} ?_{\mathrm{eq}} \Gamma\end{array}$ & $\begin{array}{l}\mathbf{X} ! a_{1}: \Gamma, \mathbf{X} ! a_{2}: \Gamma, \ldots \\
(\mathbf{X} \text { gives the canonical elements of } \Gamma) \\
\mathbf{X} ! a_{i}: \Gamma \Rightarrow a_{j}: \Gamma \\
(\mathbf{X} \text { provides a generation method for } \Gamma) \\
\left(\mathbf{X} \text { gives the equality rule for } \Gamma^{28}\right)\end{array}$ \\
\hline $\mathbf{X} ! \varphi \vee \psi:$ prop & $\begin{array}{l}\mathbf{Y} ?_{\mathrm{Fv} 1} \\
\text { or } \\
\mathbf{Y} ?_{\mathrm{F} 22}\end{array}$ & $\begin{array}{l}\mathbf{X} ! \varphi: \text { prop } \\
\mathbf{X} ! \psi: \text { prop }\end{array}$ \\
\hline $\mathbf{X} ! \varphi \wedge \psi:$ prop & $\begin{array}{l}\mathbf{Y} ?_{\mathrm{F} \wedge 1} \\
\text { or } \\
\mathbf{Y} ?_{\mathrm{F} \wedge 2}\end{array}$ & $\begin{array}{l}\mathbf{X} ! \varphi: \text { prop } \\
\mathbf{X} ! \psi: \text { prop }\end{array}$ \\
\hline $\mathbf{X} ! \varphi \rightarrow \psi:$ prop & $\begin{array}{l}\mathbf{Y} ?_{\mathrm{F} \rightarrow 1} \\
\text { or } \\
\mathbf{Y} ?_{\mathrm{F} \rightarrow 2}\end{array}$ & $\begin{array}{l}\mathbf{X} ! \varphi: \text { prop } \\
\mathbf{X} ! \psi: \text { prop }\end{array}$ \\
\hline $\mathbf{X} !(\forall x: A) \varphi(x):$ prop & $\begin{array}{l}\mathbf{Y} ?_{\mathrm{F} \forall 1} \\
\text { or } \\
\mathbf{Y} ?_{\mathrm{F} \forall 2}\end{array}$ & $\begin{array}{l}\mathbf{X} ! A: \text { set } \\
\mathbf{X} ! \varphi(x): \operatorname{prop}(x: A)\end{array}$ \\
\hline $\mathbf{X} !(\exists x: A) \varphi(x):$ prop & $\begin{array}{l}\mathbf{Y} ?_{\mathrm{F} \exists 1} \\
\text { or } \\
\mathbf{Y} ?_{\mathrm{F} \exists+\mathrm{d}}\end{array}$ & $\begin{array}{l}\mathbf{X} ! A: \text { set } \\
\mathbf{X} ! \varphi(x): \operatorname{prop}(x: A)\end{array}$ \\
\hline $\begin{array}{l}\mathbf{X} ! B(k): \text { prop } \\
(\text { for atomic } B \text { ) }\end{array}$ & $\mathbf{Y}$ ? & $\begin{array}{l}\mathbf{X} \text { sic }(n) \\
(\mathbf{X} \text { indicates that } \mathbf{Y} \text { posited it at move } n)\end{array}$ \\
\hline $\mathbf{X} ! \perp:$ prop & - & - \\
\hline
\end{tabular}

The next rule is not a formation rule per se but rather a substitution rule. ${ }^{29}$ When $\varphi$ is an elementary sentence, the substitution rule helps explaining the formation of such sentences.

\footnotetext{
${ }^{28}$ Equality rules are presented in the next section.

${ }^{29}$ It is an application of the original rule from CTT given in Ranta (1994, p.30).
} 


\section{Posit-substitution}

When a list of variables occurs in a posit with proviso, the challenger $\mathbf{Y}$ can ask $\mathbf{X}$ to substitute those variables: he does so by positing an instantiation of the proviso, in which he $(\mathbf{Y})$ is the one who chooses the instantiations for the variables. ${ }^{30}$

\begin{tabular}{|l|l|l|}
\hline Posit & Challenge & Defence \\
\hline $\mathbf{X} ! \pi\left(\mathrm{x}_{1}, \ldots, \mathrm{X}_{\mathrm{n}}\right)\left(\mathrm{x}_{\mathrm{i}}: \mathrm{A}_{\mathrm{i}}\right)$ & $\mathbf{Y} ! \tau_{1}: \mathrm{A}_{1}, \ldots, \tau_{\mathrm{n}}: \mathrm{A}_{\mathrm{n}}$ & $\mathbf{X} ! \pi\left(\tau_{1} \ldots \tau_{\mathrm{n}}\right)$ \\
\hline
\end{tabular}

A particular case of posit substitution is when the challenger simply posits the whole assumption as it is without introducing new instantiation terms. This is particularly useful in the case of formation plays: see an application in move 7 of the example p. $\sim 14$ below.

\begin{tabular}{|l|l|l|}
\hline Posit & Challenge & Defence \\
\hline $\mathbf{X} ! \pi\left(\tau_{1}, \ldots, \tau_{\mathrm{n}}\right)\left(\tau_{\mathrm{i}}: \mathrm{A}_{\mathrm{i}}\right)$ & $\mathbf{Y} ! \tau_{1}: \mathrm{A}_{1}, \ldots, \tau_{\mathrm{n}}: \mathrm{A}_{\mathrm{n}}$ & $\mathbf{X} ! \pi\left(\tau_{1}, \ldots, \tau_{\mathrm{n}}\right)$ \\
\hline
\end{tabular}

Remarks on the formation dialogues:

a) Conditional formation posits:

A crucial feature of formation rules is that they enable the displaying of the syntactic and semantic presuppositions of a given thesis which can thus be examined by the Opponent before running the actual dialogue on the thesis. For instance if the thesis amounts to positing $\varphi$, then before launching an attack, the Opponent can ask for its formation. Defending on the formation of $\varphi$ might bring the Proponent to posit that $\varphi$ is a proposition, provided that $\mathrm{A}$, for instance, is a set is conceded. In this situation the Opponent might concede $\mathrm{A}$ is a set, but only after the Proponent displayed the constitution of A.

b) Elementary sentences, definitional consistency and material-analytic dialogues:

Following the idea of formation rules through and through, the defence $\operatorname{sic}(n)$ for elementary sentences is somehow unsatisfactory as it does not really explore the formation of the expression. A defence which applies fitting predicator rules previously conceded, if such things exist, would be a possibility - see Rahman and Clerbout (2014). What would then happen is that challenges on elementary sentences would be based on the definitional consistency in the use of the predicator rules previously conceded.

Therefore, what will happen is that the challenge on elementary sentence is based on the definitional consistency in use of the conceded predicator rules. This is what we think material-dialogues are about: definitional consistency dialogues. This leads to the following material analytic rule for formation dialogues:

$\boldsymbol{O}$ 's elementary sentences cannot be challenged, however $\boldsymbol{O}$ can challenge an elementary sentence (posited by $\boldsymbol{P}$ ) iff she herself (the Opponent) did not posit it before.

\footnotetext{
${ }^{30}$ More precisely, in the case where the defender did not commit himself to the proviso, the dialogical approach allows a distinction here discussed in the next section.
} 
Remark: Once $\boldsymbol{P}$ forced $\boldsymbol{O}$ to concede the elementary sentence in the formation dialogue, the dialogue proceeds using the copy-cat strategy. The version of the rule we work with, where the defence is $\operatorname{sic}(n)$, is related to that.

By way of illustration, here is an example where the Proponent posits the thesis $(\forall x: A)(B(x) \rightarrow C(x)):$ prop given that $A: \operatorname{set}, B(x): \operatorname{prop}(x: A)$ and $C(x): \operatorname{prop}(x: A)$, where the three provisos appear as initial concessions by the Opponent. ${ }^{31}$ Normally we should give all the rules of the game before giving an example, but we make an exception here because the standard structural rules of section 2.1 are enough to understand the following plays. We can focus this way on illustrating the way formation rules can be used.

\begin{tabular}{|c|c|c|c|c|}
\hline & $\mathbf{O}$ & & $\mathbf{P}$ & \\
\hline I & $! A:$ set & & & \\
\hline II & $! B(x): \operatorname{prop}(x: A)$ & & & \\
\hline \multirow[t]{2}{*}{ III } & $! C(x): \operatorname{prop}(x: A)$ & & & \\
\hline & & & $!(\forall x: A) B(x) \rightarrow C(x):$ prop & 0 \\
\hline 1 & $n:=1$ & & $m:=2$ & 2 \\
\hline 3 & $?_{\mathrm{F} \forall 1}$ & $(0)$ & $! A$ : set & 4 \\
\hline
\end{tabular}

Explanations:

- I to III: $\boldsymbol{O}$ concedes that $A$ is a set and that $B(x)$ and $C(x)$ are propositions provided $x$ is an element of $A$,

- Move 0: $\boldsymbol{P}$ posits that the main sentence, universally quantified, is a proposition (under the concessions made by $\boldsymbol{O}$ ),

- Moves 1 and 2: the players choose their repetition ranks, ${ }^{32}$

- Move 3: $\boldsymbol{O}$ challenges the thesis by asking the left-hand part as specified by the formation rule for universal quantification,

- Move 4: $\boldsymbol{P}$ responds by positing that $A$ is a set. This has already been granted with the premise I so even if $\boldsymbol{O}$ were to challenge this posit, the Proponent could refer to this initial concession. Later on, we will introduce the structural rule SR3 to deal with this phenomenon. Thus $\boldsymbol{O}$ has no further possible move, the dialogue ends here and is won by $\boldsymbol{P}$.

\footnotetext{
${ }^{31}$ The example stems from Ranta (1994, p.31).

${ }^{32}$ The device of repetition rank is introduced in the structural rules which we present in the appendix. See also Clerbout (2014a,b,c) for detailed explanations on this notion.
} 
Obviously, this dialogue does not cover all the aspects related to the formation of $(\forall x: A) B(x) \rightarrow C(x):$ prop. Notice however that the formation rules allow an alternative move for the Opponent's move $3{ }^{33}$ Hence another possible course of action for $\boldsymbol{P}$ arises.

\begin{tabular}{|c|c|c|c|c|c|}
\hline & $\mathbf{O}$ & & & $\mathbf{P}$ & \\
\hline I & $! A:$ set & & & & \\
\hline II & $! B(x): \operatorname{prop}(x: A)$ & & & & \\
\hline \multirow[t]{2}{*}{ III } & $! C(x): \operatorname{prop}(x: A)$ & & & & \\
\hline & & & & $!(\forall x: A) B(x) \rightarrow C(x):$ prop & 0 \\
\hline 1 & $n:=1$ & & & $m:=2$ & 2 \\
\hline 3 & $?_{\mathrm{F} \forall 2}$ & $(0)$ & & $! B(x) \rightarrow C(x): \operatorname{prop}(x: A)$ & 4 \\
\hline 5 & $! x: A$ & (4) & & $! B(x) \rightarrow C(x):$ prop & 6 \\
\hline 7 & $?_{\mathrm{F} \rightarrow 1}$ & (6) & & $! B(x):$ prop & 10 \\
\hline 9 & $! B(x):$ prop & & (II) & $! x: A$ & 8 \\
\hline
\end{tabular}

\section{Explanations:}

The second dialogue starts like the first one until move 2. Then:

- Move 3: This time $\boldsymbol{O}$ challenges the thesis by asking for the right-hand part,

- Move 4: $\boldsymbol{P}$ responds, positing that $B(x) \rightarrow C(x)$ is a proposition provided $x: A$,

- Move 5: $\boldsymbol{O}$ uses the substitution rule to challenge move 4 by granting the proviso,

- Move 6: $\boldsymbol{P}$ responds by positing that $B(x) \rightarrow C(x)$ is a proposition,

- Move 7: $\boldsymbol{O}$ then challenges move 6 by asking the left-hand part as specified by the formation rule for material implication.

To defend this $\boldsymbol{P}$ needs to make an elementary move. But since $\boldsymbol{O}$ has not played it yet, $\boldsymbol{P}$ cannot defend it at this point. Thus:

- Move 8: $\boldsymbol{P}$ launches a counterattack against assumption II by applying the substitution rule,

- Move 9: $\boldsymbol{O}$ answers to move 8 and posits that $B(x)$ is a proposition,

- Move 10: $\boldsymbol{P}$ can now defend in reaction to move 7 and win this dialogue.

Then again, there is another possible path for the Opponent because she has another possible choice for her move 7, namely asking the right-hand part. This yields a dialogue similar to the one above except that the last moves are about $C(x)$ instead of $B(x)$.

\footnotetext{
${ }^{33}$ As a matter of fact increasing her repetition rank would allow her to play the two alternatives for move 3 within a single play. But increasing the Opponent's rank usually yields redundancies (Clerbout $(2014 a, b)$ ) making things harder to understand for readers not familiar with the dialogical approach. Hence our choice to divide the example into different simple plays.
} 
By displaying these various possibilities for the Opponent, we have entered the strategical level. This is the level at which the question of the good formation of the thesis gets a definitive answer, depending on whether the Proponent can always win i.e., whether he has a winning strategy. We have introduced the basic notions related to this level in the previous section. See also the end of the next section, as well as chapters 3 and 5 for more explanations.

Now that the dialogical account of formation rules has been clarified, we may further develop our analysis of plays by introducing play-objects.

\section{3 Play-objects}

The idea now is to design dialogical games in which the players' posits are of the form " $p: \varphi$ " and give their meaning by the way they are used in the game: how they are challenged and defended. This requires analysing the form of a given play-object $p$, which depends on $\varphi$, and how a play-object can be obtained from other, simpler, playobjects. The standard dialogical semantics (section 2.1) for logical constants gives us the information we need. The main logical constant of the expression at stake provides the basic information as to what a play-object for that expression consists of:

A play for $\boldsymbol{X} ! \varphi \vee \psi$ is obtained from two plays $p_{1}$ and $p_{2}$, where $p_{1}$ is a play for $\boldsymbol{X} ! \varphi$ and $p_{2}$ is a play for $\boldsymbol{X} ! \psi$. According to the standard dialogical approach to disjunction, the player $\boldsymbol{X}$ is the one who can switch from $p_{1}$ to $p_{2}$ and conversely.

A play for $\boldsymbol{X} ! \varphi \wedge \psi$ is obtained similarly, except that the player $\boldsymbol{Y}$ is the one who can switch from $p_{1}$ to $p_{2}$.

A play for $\boldsymbol{X} ! \varphi \rightarrow \psi$ is obtained from two plays $p_{1}$ and $p_{2}$, where $p_{1}$ is a play for $\boldsymbol{Y} ! \varphi$ and $p_{2}$ is a play for $\boldsymbol{X} ! \Psi$. The player $\boldsymbol{X}$ is the one who can switch from $p_{1}$ to $p_{2}$.

The standard dialogical particle rule for negation interprets $\sim \varphi$ as an abbreviation for $\varphi \rightarrow \perp$, although it is usually left implicit. From this follows that one obtains plays for $\boldsymbol{X}$ ! $\sim \varphi$ in a similar way to plays for material implication, that is from two plays $p_{1}$ and $p_{2}$, where $p_{1}$ is a play for $\boldsymbol{Y} ! \varphi, p_{2}$ is a play for $\boldsymbol{X} ! \perp$, and $\boldsymbol{X}$ can switch from $p_{1}$ to $p_{2}$. Notice that this approach covers the standard game-theoretical interpretation of negation as roleswitch: $p_{1}$ is a play for a $\boldsymbol{Y}$-move.

As for quantifiers, a detailed discussion will be given after the particle rules. We would like to point out for now that, just like what is done in constructive type theory, we are dealing with quantifiers for which the type of the bound variable is always specified. We thus consider expressions of the form $(\mathrm{Q} x: A) \varphi$, where $\mathrm{Q}$ is a quantifier symbol.

The table on next page presents the particle rules. 


\begin{tabular}{|c|c|c|}
\hline Posit & Challenge & Defence \\
\hline $\begin{array}{l}\mathbf{X} ! \varphi \\
\text { (where no play-object has been } \\
\text { specified for } \varphi \text { ) }\end{array}$ & Y ? play-object & $X ! p: \varphi$ \\
\hline \multirow[b]{2}{*}{$\mathbf{X} ! p: \varphi \vee \psi$} & $\mathbf{Y}$ ?prop & $\mathbf{X} ! \varphi \vee \psi:$ prop \\
\hline & $\mathbf{Y} ?[\varphi / \psi]$ & $\begin{array}{l}\mathbf{X} ! L^{\vee}(p): \varphi \\
\text { Or } \\
\mathbf{X} ! R^{\vee}(p): \psi \\
{[\text { the defender has the choice] }}\end{array}$ \\
\hline \multirow[b]{2}{*}{$\mathbf{X} ! p: \varphi \wedge \psi$} & $\mathbf{Y} ?_{\text {prop }}$ & $\mathbf{X} ! \varphi \wedge \psi:$ prop \\
\hline & $\begin{array}{l}\mathrm{Y} ?_{\mathrm{L}} \\
\text { Or } \\
\mathrm{Y} ?_{\mathrm{R}} \\
\text { [the challenger has the choice] }\end{array}$ & $\begin{array}{l}\mathbf{X}: \mathrm{L}^{\wedge}(\mathrm{p}): \varphi \\
\text { respectively } \\
\mathbf{X}: \mathrm{R}^{\wedge}(\mathrm{p}): \psi\end{array}$ \\
\hline \multirow[b]{2}{*}{$\mathbf{X}: p: \varphi \rightarrow \psi$} & $\mathbf{Y}$ ?prop & $\mathbf{X}: \varphi \rightarrow \psi:$ prop \\
\hline & $\mathbf{Y} ! \mathrm{L} \rightarrow(p): \varphi$ & $\mathbf{X} ! \mathrm{R}^{\rightarrow}(\mathrm{p}): \psi$ \\
\hline \multirow[b]{2}{*}{$\mathbf{X} ! \mathrm{p}: \neg \varphi$} & $\mathbf{Y}$ ?prop & $\mathbf{X} ! \neg \varphi:$ prop \\
\hline & $\mathbf{Y} ! \mathrm{L}^{\perp}(\mathrm{p}): \varphi$ & $\mathbf{X} ! \mathrm{R}^{\perp}(\mathrm{p}): \perp$ \\
\hline \multirow[b]{2}{*}{$\mathbf{X} ! p:(\exists x: A) \varphi$} & $\mathbf{Y}$ ? prop & $\mathbf{X} !(\exists \mathrm{x}: \mathrm{A}) \varphi:$ prop \\
\hline & $\begin{array}{l}\text { Y } ?_{\mathrm{L}} \\
\text { Or } \\
\mathrm{Y} ?_{\mathrm{R}} \\
\text { [the challenger has the choice] }\end{array}$ & $\begin{array}{l}X ! L^{\exists}(p): A \\
\text { Respectively } \\
X ! R^{\exists}(p): \varphi(L(p))\end{array}$ \\
\hline $\mathbf{X}: \mathrm{p}:\{\mathrm{x}: \mathrm{A} \mid \varphi\}$ & $\begin{array}{l}\mathrm{Y} ?_{\mathrm{L}} \\
\text { Or } \\
\mathrm{Y} ?_{\mathrm{R}} \\
\text { [the challenger has the choice] }\end{array}$ & $\begin{array}{l}\mathbf{X} ! \mathrm{L}^{\{\cdots\}}(\mathrm{p}): A \\
\text { Respectively } \\
\mathbf{X} ! \mathrm{R}^{\{\cdots\}}(\mathrm{p}): \varphi(\mathrm{L}(\mathrm{p}))\end{array}$ \\
\hline \multirow[b]{2}{*}{$\mathbf{X}: \mathrm{p}:(\forall \mathrm{x}: \mathrm{A}) \varphi$} & $\mathbf{Y}$ ?prop & $\mathbf{X} !(\forall \mathbf{x}: \mathrm{A}) \varphi:$ prop \\
\hline & $\mathbf{Y} ! \mathrm{L}^{\forall}(\mathrm{p}): \mathrm{A}$ & $\mathbf{X} ! \mathrm{R}^{\forall}(\mathrm{p}): \varphi(\mathrm{L}(\mathrm{p}))$ \\
\hline \multirow[b]{2}{*}{$\begin{array}{l}\mathbf{X} ! \mathrm{p}: \mathrm{B}(\mathrm{k}) \\
(\text { for atomic } \mathrm{B})\end{array}$} & $\mathbf{Y}$ ?prop & $\mathbf{X} ! \mathrm{B}(\mathrm{k}):$ prop \\
\hline & Y? & $\begin{array}{l}\mathbf{X} \operatorname{sic}(n) \\
(\mathrm{X} \text { indicates that } \mathrm{Y} \text { posited it at } \\
\text { move } n)\end{array}$ \\
\hline
\end{tabular}

Let us point out that we have added a challenge of the form $\boldsymbol{Y}$ ?prop by which the challenger questions the fact that the expression at the right-hand side of the semi-colon is a proposition. This connects back with the formation rules of the preceding section via $\boldsymbol{X}^{\prime}$ s defence. Further details will be given in the discussion after the structural rules. 
It may happen that the form of a play-object is not explicit at first. In such cases we deal with expressions of the form, e.g., " $p: \varphi \wedge \psi$ ". In the relevant challenges and defences, we then use expressions such as $L^{\wedge}(p)$ and $R^{\wedge}(p)$ used in our example. We call these expressions instructions. Their respective interpretations are "take the left part of $p "$ and "take the right part of $p$ ". In instructions we indicate the logical constant at stake: ${ }^{34}$ it keeps the formulations explicit enough, in particular in the case of embedded instructions. We must also keep in mind the important differences between play-objects depending on the logical constant that is used. Consider for example the case of conjunction and disjunction:

- A play-object $p$ for a disjunction is composed by two play-objects, but each of them constitutes a sufficient play-object for the disjunction. Moreover it is the defender who makes the choice between $L^{\vee}(p)$ and $R^{\vee}(p)$.

- A play-object $p$ for a conjunction is also composed by two play-objects, but this time the two of them are necessary to constitute the one for the conjunction. It is then the challenger's privilege to ask for either or both (provided the other rules allow him to do so).

Accordingly, $L^{\wedge}(p)$ and $L^{\vee}(p)$, say, are actually different things and the notation takes that into account.

Let us now focus on the quantifier rules. There are two distinct moments in the meaning of quantifiers, brought out by dialogical semantics: choosing a suitable substitution term for the bound variable, and instantiating the formula after replacing the bound variable with the chosen substitution term. However the standard dialogical approach tends to presuppose a unique and global collection of objects on which the quantifiers range. Things are different with the explicit language borrowed from CTT. Quantification is always relative to a set, and there are sets of many different kinds of objects (for example: sets of individuals, sets of pairs, sets of functions, etc). Owing to the instructions we can give a general form for the particle rules, and the object is specified in a third and later moment, when instructions are "resolved" by means of the structural rule SR4.1 displayed in the next section.

Constructive type theory clearly shows the basic similarity there is between conjunction and existential quantifier on the one hand and material implication and universal quantifier on the other hand, as soon as propositions are thought of as sets. Briefly, the point is that they are formed in similar ways and their elements are generated by the same kind of operations. ${ }^{35}$ In our approach, this similarity manifests itself in the fact that a play-object for an existentially quantified expression is of the same form as a play-object for a conjunction. Similarly, a play-object for a universally quantified expression is of the same form as one for a material implication. ${ }^{36}$

\footnotetext{
${ }^{34}$ If needed, we use subscripts to prevent scope ambiguities in the case of embedded occurrences of the same quantifier.

${ }^{35}$ More precisely, conjunction and existential quantifier are two particular cases of the $\Sigma$ operator (disjoint union of sets), whereas material implication and universal quantifier are two particular cases of the $\Pi$ operator (indexed product on sets). See for example Ranta (1994, chapter 2).
} 
The particle rule just before the one for universal quantification is a novelty in the dialogical approach. It involves expressions commonly used in Constructive Type Theory to deal with separated subsets. The idea is to understand those elements of $A$ such that $\varphi$ as expressing that at least one element $L^{\{\cdots\}}(p)$ of $A$ witnesses $\varphi\left(L^{\{\cdots\}}(p)\right)$. The same correspondence that linked conjunction and existential quantification now appears. ${ }^{37}$ This is not surprising since such posits actually have an existential aspect: in $\{x: A \mid \varphi\}$ the left part " $x: A$ " signals the existence of a play-object. Let us point out that since the expression stands for a set, when $\boldsymbol{X}$ posits it, it is not presupposed to be a proposition. This is why it cannot be challenged with the request "?prop".

As we previously said, in the dialogical approach to CTT every object is known as instantiating a type and this constitutes the most elementary form of assertion $a: A$. Furthermore, instructions are in fact substitution commitments close to the sense mentioned in the above quote. A thorough study is yet to be done on the substitutional approach to subsentential expressions and the role of instructions, though it would be necessary in our view for the exploration of both the formal consequences of Brandom's insights and the philosophical tenets underlying the notion of instruction.

Let us now consider the rule for the elementary case. In this rule, but also in the associated formation rule of the previous section, the defence "sic(n)" recalls that the adversary has previously made the same posit. The rule works in a similar fashion as the formal rule of the standard formulation (see appendix), except that it is applicable to both players: it is not limited to the Proponent. We say similar in the sense that the rule allows players to perform a kind of copy-cat. Once that aspect of the formal rule is settled, we can work with a modified version of the rule which we will introduce with more explanations in the next section.

Despite the similarity we have just mentioned, there is a crucial difference with standard dialogical games. Elementary sentences are associated with play-objects, and one such sentence can be associated with many different play-objects in actual courses of the game. Therefore, and this is a most important point, the defence "sic $(n)$ " does not express a copy-cat on the elementary sentence alone, but on the whole posit. We thus have a game rule such that, for a given elementary sentence, there are as many ways to give reasons for it (to defend it) as there are play-objects for it. Formulating the rule with the defence "sic(n)" is very different from merely integrating the standard formal rule at the local level: "sic(n)" is an abbreviation useful to provide an abstract rule, but because play-objects are introduced, it actually embodies a fully fledged semantics in terms of asking for and giving reasons.

\footnotetext{
${ }^{36}$ Still, if we are playing with classical structural rules, there is a slight difference between material implication and universal quantification which we take from Ranta (1994, Table 2.3), namely that in the second case $\mathrm{p}_{2}$ always depends on $\mathrm{p}_{1}$.

${ }^{37}$ As pointed out in Martin-Löf (1984), subset separation is another case of the $\Sigma$ operator. See in particular p.53:

Let $A$ be a set and $B(x)$ a proposition for $x \in A$. We want to define the set of all $a \in A$ such that $B(a)$ holds (which is usually written $\{x \in A: B(x)\})$. To have an element $a \in A$ such that $B(a)$ holds means to have an element $a \in A$ together with a proof of $B(a)$, namely an element $b \in B(a)$. So the elements of the set of all elements of $A$ satisfying $B(x)$ are pairs $(a, b)$ with $b \in B(a)$, i.e., elements of $(\Sigma \mathrm{x} \in \mathrm{A}) \mathrm{B}(\mathrm{x})$. Then the $\Sigma$-rules play the role of the comprehension axiom (or the separation principle in $Z F$ ).
} 
So far, apart from the rule for subset-separation and the rule for elementary sentences, we have mostly adapted the rules of standard dialogical games to the explicit language we are working with. Now because of the explicit nature of this language, there are more rules related to the meaning explanations of play-objects and types. The next rules involve what is known in CTT as definitional equality. These rules introduce a different kind of provisional clause, namely a clause in which the defender is the player committed to the expression within the clause and thus he, rather than the challenger, will eventually posit it. In standard CTT there is no need for such a distinction since there are no players. However, in dialogical games the distinction can and must be made depending on who posits the proviso. Accordingly we use of the notation $<\ldots>$ to signal that it is the player making the posit who is committed to the expression in the proviso clause and (...) when it is the opponent.

We have already considered the latter case in this section. Let $\pi$ be a posit and $<\ldots>$ a proviso which the utterer is committed to. The general form of the rule for provisos is the following:

\begin{tabular}{|l|l|l|}
\hline Posit & Challenge & Defence \\
\hline $\mathbf{X} ! \pi<\ldots>$ & $\mathbf{Y} ?_{[\pi]}$ & $\mathbf{X} ![\pi]$ \\
& $\mathbf{O r}$ & $\mathbf{X} ![<\ldots>]$ \\
\hline $\mathbf{Y} \boldsymbol{?}_{[<\ldots>]}$ & $\begin{array}{l}\text { where } ?[\pi] \text { and } ![\pi] \text { stand respect- } \\
\text { ively for the relevant challenge or } \\
\text { defence against } \pi, \text { and similarly } \\
\text { for } ?[<>], ![<>]\end{array}$ & \\
\hline
\end{tabular}

In the initial posit, $\boldsymbol{X}$ commits himself to both $\pi$ and the proviso. Hence $\boldsymbol{Y}$ is entitled to question either one, and he is the one to choose which to ask for. The rule states that the challenger can question either part of the initial posit, and that in each case he does so depending on the form of the expression. An illustration is helpful here. Assume the initial posit is $p:(\forall x: A) B(x)<c: C>$ which reads "given $c: C$ we have $B(x)$ for all $x: A$; and the player making the posit commits himself to the proviso". Then the rule is applied as described in the next table.

\begin{tabular}{|l|l|l|}
\hline Posit & Challenge & Defence \\
\hline $\mathbf{X} ! \mathrm{p}:(\forall \mathrm{x}: \mathrm{A}) \mathrm{Bx}<\mathrm{c}: \mathrm{C}>$ & $\mathbf{Y} ? \mathrm{~L}^{\forall}(\mathrm{p}): \mathrm{A}$ & $\mathbf{X} ! \mathrm{R}^{\forall}(\mathrm{p}): \mathrm{B}(\mathrm{L}(\mathrm{p}))$ \\
\hline $\mathbf{O r}$ & $\mathbf{X}$ sic (n) \\
& $\mathbf{Y} \boldsymbol{P}_{[\mathrm{c}: \mathrm{C}]}$ & $\begin{array}{l}\text { where } ?[\pi] \text { and } ![\pi] \text { stand respect- } \\
\text { ively for the relevant challenge or } \\
\text { defence against } \pi, \text { and similarly } \\
\text { for } ?[<>], ![<>]\end{array}$ \\
\hline
\end{tabular}


In this case, $\pi$ involves universal quantification and the proviso is the elementary posit $c$ : $C$. Thus, the first possible challenge for $\boldsymbol{Y}$ consists in applying the particle rule for universal quantification, whereas the second possible challenge is done by applying the rule for elementary posits. The possible defences by $\boldsymbol{X}$ are then in turn determined by these rules.

A typical case in which provisos of the form $<\ldots>$ occur is functional substitution. Assume some function $f$ has been introduced, for example with $f(x): B(x: A)$. When a player uses $f(a)$ in a posit, for some $a: A$, the antagonist is entitled to ask him what the output substitution-term of $f$ is, given the substitution-term $a$ as input. Now $f(a)$ can be used either at the left or at the right of the colon. Accordingly we have two rules:

(Function-substitution)

\begin{tabular}{|l|l|l|}
\hline Posit & Challenge & Defence \\
\hline $\mathbf{X} ! \mathrm{f}(\mathrm{a}): \varphi$ & $\mathbf{Y} \mathrm{f}(\mathrm{a}) ? \Leftrightarrow$ & $\mathbf{X} ! \mathrm{f}(\mathrm{a}) / \mathrm{ki}: \varphi<\mathrm{f}(\mathrm{a})=\mathrm{ki}: \mathrm{B}>$ \\
\hline $\mathbf{X} ! \alpha: \varphi[\mathrm{f}(\mathrm{a})]$ & $\mathbf{Y} \mathrm{f}(\mathrm{a}) / ? \Leftrightarrow=>$ & $\mathbf{X} ! \alpha: \varphi[\mathrm{f}(\mathrm{a}) / \mathrm{ki}]<\varphi[\mathrm{f}(\mathrm{a})]=\varphi[\mathrm{f}(\mathrm{a}) / \mathrm{ki}]:$ set $>$ \\
\hline
\end{tabular}

The subscript ' $\angle>$ ' in the challenges indicates that the substitution is related to some equality, and the defender endorses an equality in the proviso of the defence. The second rule - where $\alpha$ can be a play-object or an instruction - is applied in the dialogical take on the Axiom of Choice. See the "second play" in section II.

Important remark: These two rules express a double commitment for the defender who is committed to the proviso in the defence. One might therefore argue that the rules could also be formulated as involving two challenges (and two defences). There are however two problems with such an approach. For illustration purposes, let us consider such a formulation of the second rule involving two steps:

\begin{tabular}{|lll|}
\hline Posit & Challenge & Defence \\
\hline $\mathbf{X} ! \alpha: \varphi[\mathrm{f}(\mathrm{a})]$ & $\mathbf{Y} ! \mathrm{L}(\mathrm{f}(\mathrm{a})) / ?$ & $\mathbf{X} ! \mathrm{p}: \varphi[\mathrm{f}(\mathrm{a}) / \mathrm{ki}]$ \\
& $\mathbf{Y} ! \mathrm{R}(\mathrm{f}(\mathrm{a})) / ?$ & $\mathbf{X} ! \varphi[\mathrm{f}(\mathrm{a})]=\varphi[\mathrm{f}(\mathrm{a}) / \mathrm{ki}]:$ set \\
\hline
\end{tabular}

The first problem is that the second challenge works as if the proviso $\varphi[f(a)]=\varphi\left[f(a) / k_{i}\right]$ : set was implicit in the initial posit and had to be made explicit. However this is a slightly misguided approach since the proviso does not concern the initial posit: the proviso must be established only after $\boldsymbol{X}$ has chosen $k_{i}$ for the substitution. The second problem is related to the first: in such a formulation the challenger is the one who can choose between asking $\boldsymbol{X}$ to perform the substitution and asking him to posit the proviso. It thus allows the challenger to perform just the second challenge without asking for the substitution, which brings us back to the first problem. Moreover, introducing a choice for one of the players results, when the rule can be applied, in multiplying the number of alternative plays (in particular when the repetition rank of the challenger is 1). For all these reasons, such an alternative formulation is less satisfactory than the one we gave above. 
Functional substitution is closely related to the $\Pi$-Equality rule, which we now introduce together with $\Sigma$ and $\vee$-Equality.

( $\Pi$-Equality) We use the CTT notation $\Pi$ which covers the cases of universal quantification and material implication.

\begin{tabular}{|l|l|l|}
\hline Posit & Challenge & Defence \\
\hline $\mathbf{X} ! \mathrm{p}:(\Pi \mathrm{x}: \mathrm{A}) \varphi$ & & \\
$\mathbf{Y} ! \mathrm{L}^{\Pi}(\mathrm{p}) / \mathrm{a}: \mathrm{A}$ & & $\mathbf{X} ! \mathrm{p}(\mathrm{a})=\mathrm{R}^{\Pi}(\mathrm{p}): \varphi(\mathrm{a} / \mathrm{x})$ \\
$\mathbf{X} ! \mathrm{R}^{\Pi}(\mathrm{p}): \varphi(\mathrm{a} / \mathrm{x})$ & $\mathbf{Y} ?_{\Pi-\mathrm{Eq}}$ & \\
\hline
\end{tabular}

( $\Sigma$-Equality) The rule is similar for existential quantification, subset separation, and conjunction. Thus we use the notation from CTT which uses the $\Sigma$ operator. In the following rule $I^{\Sigma}$ can be either $L^{\Sigma}$ or $R^{\Sigma}$, and $i$ can be either 1 or 2 . Moreover, it is 1 when $I$ is $L$ and 2 when $I$ is $R$.

\begin{tabular}{|c|c|c|}
\hline Posit & Challenge & Defence \\
\hline $\begin{array}{l}\mathrm{X} ! \mathrm{p}:\left(\Sigma \mathrm{x}: \varphi_{1}\right) \varphi_{2} \\
\mathrm{Y} \mathrm{I}^{\Sigma}(\mathrm{p}) / ? \\
\mathrm{X} ! \mathrm{p}_{\mathrm{i}} / \mathrm{I}^{\Sigma}(\mathrm{p}): \varphi_{\mathrm{i}}\end{array}$ & $\mathbf{Y} ?_{\Sigma-\mathrm{Eq}}$ & $\mathbf{X}: \mathrm{I}^{\Sigma}(\mathrm{p})=\mathrm{p}_{\mathrm{i}}: \varphi_{\mathrm{i}}$ \\
\hline
\end{tabular}

Notice that these rules have several preconditions: there is no lone initial posit triggering the application of the rule. From a dialogical perspective, these rules intend to allow the challenger to take advantage from information from the history of the current play - including resolutions of instructions - to make $\boldsymbol{X}$ posit some equality. For an application, see the second play in section II where the $\Pi$-Equality rules play a prominent role.

These rules strongly suggest a close connection between the CTT equality rules for logical constants and the dialogical instructions through what we will call in the next section their resolution.

In fact, equality rules can be seen as making explicit the use of the formal rule in relation to the task of carrying out instructions. Hence, under this perspective, identities express explicitly some specific forms of interaction. Let us briefly discuss this point:

Assume that the Proponent brings forward the thesis that if the Opponent concedes the conjunction, say $A \wedge B$, he (the Proponent) will be able to successfully defend the assertion $B \wedge A$, that is, that $\mathbf{P}$ has a winning strategy for the commutative transformation of the conjunction. Let us present informally the dialogical development of this thesis:

1. $\mathbf{O} ! p: A \wedge B$ (concession)

2. $\mathbf{P} ! q: B \wedge A$

3. $\mathbf{O} ?_{\mathrm{L}}$ (the Opponent launches his challenge asking for the left component)

4. $\quad \mathbf{P} ! L^{\wedge}(q): B$

5. $\quad \mathbf{O} L^{\wedge}(q) /$ ? ( $\mathbf{O}$ asks $\mathbf{P}$ to carry out the instruction by picking out one play-object)

6. Since we are focusing on a winning strategy, we will assume that $\mathbf{P}$ makes the smartest move, and this is certainly to launch a counter-attack: the idea is to force $\mathbf{O}$ to choose a play-object first and then copy-cat it, before he goes on to answer the challenge of move 5:

$\mathbf{P} ?_{\mathrm{R}}$

7. $\mathbf{O} ! R^{\wedge}(p): B$ 
8. $\quad \mathbf{P} R^{\wedge}(p) /$ ? (P asks $\mathbf{O}$ to carry out the instruction by picking out one play-object for the right side of the conjunction)

9. $\mathbf{O} ! b: B(\mathbf{O}$ carries out the instruction by choosing the play-object $b$ )

10. Now the Proponent has the information he needed, and copies the Opponents choice to answer $\mathbf{O}$ 's challenge stated at move 5:

$\mathbf{P} ! b: B$

(It should be clear that a similar end will happen if $\mathbf{O}$ starts by challenging the right component of the conjunction-posit)

Now, let us try to make explicit what happened. The point is that the Proponent is in fact considering the right part of $p$ as definitionally equal to the left part of $q$. If we were to make explicit this move, the following definitional equality will come out:

$$
R^{\wedge}(p)=L^{\wedge}(q): B
$$

The influence of the definitional equality of play-objects on the equality of propositions is exemplified at its best in the case of quantifiers. Take for instance, the thesis that there is a $\mathbf{P}$-winning strategy for $p:(\exists x: A) B x$ if the Opponent concedes $q:(\forall x: A) B x$. The core of the winning strategy is based on the fact that the Proponent can choose for the resolution of the instruction for the first component of the existential the same play-object that resolves the instruction of the first component of the universal posited by $\mathbf{O}$. The explicit formulation of this process amounts to the Proponent making use of the equality $L^{\exists}(p)=L^{\forall}(q)$. Now, since the resolution of $L^{\forall}(q)$ will spread to $\mathrm{B}\left(L^{\forall}(q)\right)$, we will have as a result that $\mathrm{B}\left(L^{\forall}(q)\right)$ and $\mathrm{B}\left(L^{\exists}(p)\right)$ are equal propositions. ${ }^{38}$

The task ahead is to formulate rules that implement this explicitation-process as part of the development of a play. In the meanwhile let us display all the rules that determine explicit identity-expressions:

\section{(Reflexivity within set)}

\begin{tabular}{|c|l|l|}
\hline Posit & Challenge & Defence \\
\hline $\mathbf{X} ! \dot{A}:$ set & $\mathbf{Y}$ ?set $^{- \text {refl }}$ & $\mathbf{X}: \mathrm{A}=\mathrm{A}:$ set \\
\hline
\end{tabular}

${ }^{38}$ One non negligible result of the interactive roots of definitional equality is that it provides a new insight into the dialogical take on the CTT approach to the notion of harmony as developed in Rahman/Redmond (2015). Indeed, since the CTT approach to harmony, as mentioned above, is based on coordinating the elimination and introduction rule by means of definitional equality, and the latter, according to our analysis, corresponds to the strategic use of the formal rule, it follows that CTT- harmony is based on the strategic use of copy-cat interaction. Moreover, since, as argued in Rahman/Redmond (2015), harmony in general can be achieved by the more fundamental notion of player-independence, the present analysis stresses the contribution of the dialogical theory of meaning that allows distinguishing the strategic use of definitional equality from a more basic notion of harmony. Perhaps we should speak of two different notions of harmony, one of them strategic (based on copy-cat plus definitional equality) and one semantic one (based on player-independence). 
(Symmetry within set)

\begin{tabular}{|c|c|c|}
\hline Posit & Challenge & Defence \\
\hline $\mathbf{X} ! \mathrm{A}=\dot{\mathrm{B}}:$ set & $\mathbf{Y}$ ? $\mathrm{B}^{-}$symm & $\mathbf{X}: \mathrm{B}=\mathrm{A}:$ set \\
\hline
\end{tabular}

(Transitivity within set)

\begin{tabular}{|c|l|l|}
\hline \multicolumn{1}{|l|}{ Posit } & Challenge & Defence \\
\hline $\begin{array}{l}\mathbf{X} ! \mathrm{A}=\mathrm{B}: \text { set } \\
\mathbf{X} ! \mathrm{B}=\mathrm{C}: \text { set }\end{array}$ & $\mathbf{Y} ?_{\mathrm{A}^{-} \text {trans }} \mathbf{X} ! \mathrm{A}=\mathrm{C}:$ set \\
\hline
\end{tabular}

(Reflexivity within $A$ )

\begin{tabular}{|l|l|l|}
\hline & Challenge & Defence \\
\hline $\mathbf{X} ! \dot{a}: \mathbf{A}$ & $\mathbf{Y} ?$ a refl & $\mathbf{X} ! \mathrm{a}=\mathrm{a}: \mathrm{A}$ \\
\hline
\end{tabular}

(Symmetry within $A$ )

\begin{tabular}{|l|l|l|}
\hline Posit & Challenge & Defence \\
\hline $\mathbf{X} ! \mathrm{a}=\mathrm{b}: \mathrm{A}$ & $\mathbf{Y}-?_{\mathrm{b}}-$ symm & $\mathbf{X} ! \mathrm{b}=\mathrm{a}: \mathrm{A}$ \\
\hline
\end{tabular}

(Transitivity within $A$ )

\begin{tabular}{|c|c|c|}
\hline Posit & Challenge & Defence \\
\hline $\begin{array}{l}\mathbf{X} ! \mathrm{a}=\mathrm{b}: \mathrm{A} \\
\mathbf{X} ! \mathrm{b}=\mathrm{c}: \mathrm{A}\end{array}$ & $\mathbf{Y}-? \mathrm{a}^{-}-\operatorname{trans}$ & $\mathbf{X} ! \mathrm{a}=\mathrm{c}: \mathrm{A}$ \\
\hline
\end{tabular}

(Set-equality / Extensionality)

\begin{tabular}{|c|c|c|}
\hline Posit & Challenge & Defence \\
\hline & $\mathbf{Y}-?_{\text {ext }}-\mathrm{a}: \mathrm{A}$ & $\mathbf{X}-\mathrm{a}: \mathrm{B}$ \\
& $\mathrm{Y}-?_{\mathrm{ext}-\mathrm{a}} \mathrm{a}=\mathrm{b}: \mathrm{A}$ & $\mathbf{X} ! \mathrm{a}=\mathrm{b}: \mathrm{B}$ \\
\hline
\end{tabular}


(Set-substitution)

\begin{tabular}{|c|c|c|}
\hline \multicolumn{1}{|l|}{ Posit } & Challenge & Defence \\
\hline $\mathbf{X} ! \mathrm{B}(\mathrm{x}): \operatorname{set}(\mathrm{x}: \mathrm{A})$ & $\mathbf{Y} ! \mathrm{x}=\mathrm{a}: \mathrm{A}$ & $\mathbf{X} ! \mathrm{B}(\mathrm{x} / \mathrm{a}):$ set \\
\hline $\mathbf{X} ! \mathrm{B}(\mathrm{x}): \operatorname{set}(\mathrm{x}: \mathrm{A})$ & $\mathbf{Y} ! \mathrm{a}=\mathrm{c}: \mathrm{A}$ & $\mathbf{X} ! \mathrm{B}(\mathrm{a})=\mathrm{B}(\mathrm{c}):$ set \\
\hline $\mathbf{X} ! \mathrm{b}(\mathrm{x}): \mathrm{B}(\mathrm{x})(\mathrm{x}: \mathrm{A})$ & $\mathbf{Y} ! \mathrm{a}: \mathrm{A}$ & $\mathbf{X} ! \mathrm{b}(\mathrm{a}): \mathrm{B}(\mathrm{a})$ \\
\hline $\mathbf{X} ! \mathrm{b}(\mathrm{x}): \mathrm{B}(\mathrm{x})(\mathrm{x}: \mathrm{A})$ & $\mathbf{Y} ! \mathrm{a}=\mathrm{c}: \mathrm{A}$ & $\mathbf{X} ! \mathrm{b}(\mathrm{a})=\mathrm{b}(\mathrm{c}): \mathrm{B}(\mathrm{a})$ \\
\hline
\end{tabular}

In these last rules, we have considered the simpler case where there is only one assumption in the proviso or context. The rules can obviously be generalized for provisos featuring multiple assumptions.

This ends the presentation of the dialogical notion of play-object and of the rules which give an abstract description of the local proceeding of dialogical games. Next we consider the global conditions taking part in the development of dialogical plays.

\section{4 The development of a play}

We will deal in this section with the other kind of dialogical rules called structural rules. These rules govern the way plays globally proceed and are therefore an important aspect of dialogical semantics. We will work with the following structural rules:

SR0 (Starting rule). Any dialogue starts with the Opponent positing initial concessions, if any, and the Proponent positing the thesis. After that the players each choose a positive integer called repetition ranks.

SR1i (Intuitionisitic Development rule). Players move alternately. After the repetition ranks have been chosen, each move is a challenge or a defence in reaction to a previous move and in accordance with the particle rules. The repetition rank of a player bounds the number of challenges he can play in reaction to a same move. Players can answer only against the last non-answered challenge by the adversary. ${ }^{39}$

SR2 ("Priority to formation" rule). $\boldsymbol{O}$ starts by challenging the thesis with the request '?prop'. The game then proceeds by applying the formation rules first so as to check that the thesis is indeed a proposition. After that the Opponent is free to use the other local rules insofar as the other structural rules allow it.

SR3 (Modified Formal rule). $\boldsymbol{O}$ 's elementary sentences cannot be challenged. However, $\boldsymbol{O}$ can challenge a $\boldsymbol{P}$-elementary move provided she did not herself play it before.

Since we have particle rules for elementary sentences involving the defence "sic(n)" we have no need for a formal rule which entitles a player to copy-cat some moves of the adversary. ${ }^{40}$ We must however also ensure that the strictly internal aspect related to the idea of Geltung in the dialogical approach to meaning is not lost, and that

${ }^{39}$ This last clause is known as the Last Duty First condition, and is the clause making dialogical games suitable for Intuitionistic Logic, hence the name of this rule. 
the asymmetry between the player $\boldsymbol{P}$ who brings forward the thesis and his adversary $\boldsymbol{O}$ is accounted for. This is why the standard formal rule is replaced by this modified version.

SR4.1 (Resolution of instructions). Whenever a player posits a move in which instructions $I_{1}, \ldots, I_{n}$ occur, the other player can ask him to replace these instructions (or some of them) by suitable play-objects.

If the instruction (or list of instructions) occurs at the right of the colon and the posit is the tail of an universally quantified sentence or of an implication (so that these instructions occur at the left of the colon in the posit of the head of the implication), then it is the challenger who can choose the play-object. In these cases the player who challenges the instruction is also the challenger of the universal quantifier and/or of the implication.

Otherwise it is the defender of the instructions who chooses the suitable playobject. That is:

\begin{tabular}{|l|l|l|}
\hline Posit & Challenge & Defence \\
\hline $\mathrm{X} \pi\left(\mathrm{I}_{1}, \ldots, \mathrm{I}_{\mathrm{n}}\right)$ & Y $\mathrm{I}_{1}, \ldots, \mathrm{I}_{\mathrm{m}} / ? \quad(\mathrm{~m} \leq \mathrm{n})$ & $\begin{array}{l}\mathbf{X} \pi\left(\mathrm{b}_{1}, \ldots, \mathrm{b}_{\mathrm{m}}\right) \\
- \text { if the instruction occurring at } \\
\text { the right of the colon is the tail } \\
\text { of either aniversal or an } \\
\text { implication (such that } \mathrm{I}_{1}, \ldots, \mathrm{I}_{\mathrm{n}}\end{array}$ \\
& $\begin{array}{l}\text { also occur at the left of the } \\
\text { colon in the posit of the head) } \\
\text { then } \mathbf{b}_{1}, \ldots, \mathbf{b}_{\mathbf{m}} \text { are chosen } \mathbf{b y} \\
\text { the challenger }\end{array}$ \\
& $\begin{array}{l}\text { - Otherwise the defender } \\
\text { chooses }\end{array}$ \\
\hline
\end{tabular}

Important remark. In the case of embedded instructions $I_{l}\left(\ldots\left(I_{k}\right) \ldots\right)$, the substitutions are thought of as being carried out from $I_{k}$ to $I_{l}$ : first substitute $I_{k}$ with some play-object $b_{k}$, then $I_{k-1}\left(b_{k}\right)$ with $b_{k-1}$ etc. until $I_{l}\left(b_{2}\right)$. If such a progressive substitution has already been carried out once, a player can then replace $I_{l}\left(\ldots\left(I_{k}\right) \ldots\right)$ directly.

SR4.2 (Substitution of instructions). During the play, when the play-object $b$ has been chosen by any of the two players for an instruction $I$, and player $\boldsymbol{X}$ makes any posit $\pi(I)$, then the other player can ask to substitute $I$ with $b$ in this posit.

\footnotetext{
${ }^{40}$ But let us insist once more on the important point we raised in section 2.3: contrary to standard dialogical games, copy-cat does not apply only to elementary sentences but to posits in which such sentences are associated with play-objects.
} 


\begin{tabular}{|l|l|l|}
\hline Posit & Challenge & Defence \\
\hline $\begin{array}{l}\mathbf{X} \pi(\mathrm{I}) \\
\text { (where I/b has been } \\
\text { previously established) }\end{array}$ & $\mathbf{Y} ? \mathrm{I} / \mathrm{b}$ & $\mathbf{X} \pi(\mathrm{b})$ \\
\hline
\end{tabular}

The idea is that the resolution of an instruction yields a certain play-object for some substitution term, and therefore the same play-object can be assumed to result from any other occurrence of the same substitution term: instructions, after all, are functions and must yield as such the same play-object for the same substitution term.

SR5 (Winning rule for plays). For any $p$, a player who posits " $p: \perp$ " looses the current play. Otherwise the player who makes the last move in a dialogue wins it.

In comparison to the rules of standard dialogical games, some additions in the rules we just gave have been made, namely SR2 and SR4.1-2. Also, the formal rule (here SR3) and the winning rule are a bit different. Since we made explicit the use of $\perp$ in our games, we need to add a rule for it: the point is that positing falsum leads to immediate loss. We could say that it amounts to a withdrawal. ${ }^{41}$ Hence the formulation of the winning rule for plays above.

We need the rules SR4.1 and SR4.2 because of some features of CTT's explicit language. In CTT it is possible to account for questions of dependency, scope, etc. directly at the language level. In this way various puzzles, such as anaphora, get a convincing and successful treatment. The typical example, considered below, is the socalled donkey sentence "Every man who owns a donkey beats it". The two rules account for the way play-objects can be ascribed to what we have called instructions. See the dialogue in section III.2 for an application.

The rule SR2 is consistent with the common CTT practice to start demonstrations by checking or establishing the formation of propositions before proving their truth. Notice that this step also covers the formation of sets - membership, generation of elements, etc. - occurring in hypothetical posits and in quantifiers. In the current study, however, we can overlook this rule since we have restricted this work to the valid fragment of CTT: we can take it for granted that expressions are well formed. We will therefore only consider cases for which it is not necessary to carry out the formation steps since even if they were carried out, the players would always be able to justify that their expressions are well formed. We will, for this, always take examples guaranteeing, by the hypotheses introduced as initial concessions by the Opponent at the beginning of the play, that the expressions used are well formed.

What is more, it seems like we could liberalise the rule SR2. But because of the number of rules we have introduced, verifying this carefully is a delicate task that we will not carry out in this study. Let us for now simply mention that it seems sensible enough in dialogues to combine more freely the process linked to the formation rules with the development of a play. It does in fact seem perfectly consistent with actual practices questioning the status of expressions introduced in the course of the game. Suppose for example that player $\boldsymbol{P}$ has posited ' $p: \varphi \vee \psi$ '. As soon as he has posited that the

${ }^{41}$ See Keiff (2007). 
disjunction is a proposition - i.e., as soon as he has posited ' $\varphi \vee \psi$ : prop' - the other player knows how to challenge the disjunction and should be free to either keep on exploring the formation of the expression or to challenge the first posit. The point is that in a way it makes more sense to check whether $\varphi$ is a proposition or not once (or if) $X$ posits it to defend the disjunction. Doing so in a 'monological' framework such as CTT would probably bring various confusions, but the dialogical approach to meaning should quite naturally allow this additional dynamic aspect. Nonetheless, in order to generalise the equivalence result we have investigated here beyond the valid fragment of CTT (the reason why we have introduced rule SR2), it seems sensible in our view to clearly distinguish in a fashion close to CTT the steps linked to the formation from the other aspects of meaning.

The definitions of plays, games and strategies are the same as those given in section I.1. Let us now recall them. A play for $\varphi$ is a sequence of moves in which $\varphi$ is the thesis posited by the Proponent and which complies with the game rules. The dialogical game for $\varphi$ is the set of all possible plays for $\varphi$ and its extensive form is nothing but its tree representation. Thus, every path in this tree which starts with the root is the linear representation of a play in the dialogical game at stake.

We say that a play for $\varphi$ is terminal when there is no further move allowed for the player whose turn it is to play. A strategy for player $\boldsymbol{X}$ in a given dialogical game is a function which assigns a legal $\boldsymbol{X}$-move to each non terminal play where it is $\boldsymbol{X}^{\prime}$ s turn to move. When the strategy is a winning strategy for $\boldsymbol{X}$, the application of the function turns those plays into terminal plays won by $\boldsymbol{X}$. It is common practice to consider in an equivalent way an $\boldsymbol{X}$-strategy $\mathbf{s}$ as the set of terminal plays resulting when $\boldsymbol{X}$ plays according to $\mathbf{s}$. The extensive form of $\mathbf{s}$ is then the tree representation of that set. For more explanations on these notions, see Clerbout[2014c]. The equivalence result between dialogical games and CTT is established by procedures of translation between extensive forms of winning strategies.

We have explained that the view of propositions as sets of winning strategies overlooks the level of plays and that an account more faithful to the dialogical approach to meaning is that of propositions as sets of play-objects. But play-objects are not the dialogical counterparts of CTT proof-objects, and thus are not enough to establish the connection between the dialogical and the CTT approach.

The local rules of our games - that is, the formation rules together with the particle rules - exhibit some resemblances to the CTT rules, especially if we read the dialogical rules backwards. But in spite of the resemblances, play-objects are in fact very different from CTT proof-objects. The case where the difference is obvious is implication - and thus universal quantification, which is similar. In the CTT approach, a proof-object for an implication is a lambda-abstract, and a proof-object of the tail of the implication is obtained by applying the function to the proof-object of the head. But in our account with play-objects, nothing requires that the play-object for the right-hand part is obtained by the application of some function.

From this simple observation it is clear that the connection between our games and CTT is not to be found at the level of plays. In fact it is well known that the connection between dialogues and proofs is to be found at the level of strategies (see, for example, (Rahman, Clerbout and Keiff 2009) for a discussion in relation to natural deduction). Even without the question of the relation to CTT, the task of describing and 
explaining the level of strategies is required, since it is a proper and important level of meaning analysis in the dialogical framework. This work has been developed in a recent volume (Clerbout/Rahman 2015), where a precise algorithm has been described that leads from winning strategies to CTT-demonstrations and back.

Summing up, we have play-objects which carry the interactive aspects of meaning-explanations. A proposition is the set of all possible play-objects for it, and a strategy in a game about this proposition is some subset of play-objects for it.

\section{The Dialogical Take on the Axiom of Choice}

In the present section we confront Per Martin- Löf's analysis of the Axiom of Choice with Jaakko Hintikka's (1996) views on this axiom, who, to the best of our knowledge, was the first to provide a game-theoretical interpretation of it. Hintikka claims that his Game-Theoretical semantics (GTS) for Independence Friendly Logic justifies Zermelo's Axiom of Choice in a first-order way perfectly acceptable for the epistemic perspective of the constructivists. In fact, as pointed out by Jovanovic (2014) Martin-Löf's results lead to the following considerations:

1) Hintikka's preferred version of the Axiom of Choice is indeed acceptable for the constructivists and its meaning does not involve higher order logic.

2) However, the version acceptable for intuitionists is based on an intensional take on functions. From the point of view of Martin-Löf's intuitionistic approach, extensionality is the heart of the classical understanding of Zermelo's axiom and this is the real reason behind the rejection of it.

3) More generally, dependence and independence features that motivate IF-Logic, can be formulated within the frame of constructive type theory (CTT) without paying the price of a system that is neither axiomatizable nor has an underlying theory of inference - logic is about inference after all.

In this context it should be mentioned that very recent publications show that even in the frame of an extensional but constructive understanding of type theory the Axiom of Choice obtains (Sterling 2015). According to this perspective, the blame on Zermelo's axiom comes not from extensionality but from the unjustified assumption that the functionality of the relation in the antecedent, defined for specific setoids (roughly, extensional sets with a defined equivalence relation) yields a function that ranges over arbitrary quotient sets. It is this, so to say, over-generalization that is equivalent to the assumption of the third excluded. Hence, once more, the results show that there is no way to defend the evidence of Zermelo's axiom (we mean: its apparent logical validity) and defend at the same time third excluded. In the following sections we will develop the intuitionistic and intensional perspective of Martin-Löf rather than the constructivist extensional one. The latter deserves a thorough separate discussion that will not be deployed in the present paper. 


\section{1 Two plays on the Axiom of Choice}

Since the work of Martin-Löf (1984, pp. 50-51) the intensional formulation of the Axiom of Choice is evident in the sense that is logically valid. As pointed out by Bell $(2009, \mathrm{p}$. 206) its logical validity entitles us to call it an axiom rather than a postulate (as in its classical or extensional version, that is not valid). ${ }^{42}$ Jovanovic (2014) showed that, if we were to make explicit the domain and codomain of the function at the object language level, Hintikka's own formulation amounts to the following one - which for Hintikka's dismay is the intensional version of the $\mathrm{AC}$ as brought forward by Martin-Lof: ${ }^{43}$

$$
(\forall x: A)(\exists y: B(x)) C(x, y) \rightarrow(\exists f:(\forall x: A) B(x))(\forall x: A) C(x, f(x))
$$

Before developing exhaustively the winning strategy for the intensional Axiom of Choice let us formulate the idea behind the dialogical approach by emulating MartinLöf's (1984, p. 50) ${ }^{44}$ own presentation of the informal constructive demonstration of it.

From the dialogical point of view the point is that $\mathbf{P}$ can copy-cat $\mathbf{O}$ 's choice for $y$ in the antecedent for his defence of $f(x)$ in the consequent since both are equal objects of type $B(x)$, for any $x: A$. Thus, a winning strategy for the implication follows simply from the meaning of the antecedent. This meaning is defined by the dependences generated by the interaction of choices involving the embedding of an existential quantifier in a universal one:

- Let us assume that the Opponent launches an attack on the implication and accordingly posits its antecedent - the play object for the antecedent being $L^{\rightarrow}(p)$. Let us further assume that with her challenge $\mathbf{O}$ resolves the instruction $L^{\rightarrow}(p)$, by choosing $v$.

- Then for any $x: A$ chosen by $\mathbf{P}$, there must be a play-object for the right component of $v\left(R^{\forall}(v)\right.$, occurring in the antecedent.

- However, the play-object $R^{\forall}(v)$ (the right component of $v$ ) is a play-object for an existential and is thus composed by two play-objects such that the first one $\left(L^{\exists}\left(R^{\forall}(v)\right)\right.$, for any $x: A$ is of type $B(x)$. and its right component, is, for any $x: A$, of type $C\left(x, L^{\exists}\left(R^{\forall}(v)\right)\right.$.

- Now, let $\mathbf{P}$ choose precisely the same play-object $v$ for his defence of the existential in the consequent - the play-object for the consequent being $R^{\rightarrow}(p)$. Accordingly, the left play-object for the existential in the consequent is, for any $a: A$, of type $B(x)$. Thus, the left component of the playobject for the existential in the consequent is of the same type as the left component of the existential in the antecedent. Moreover, since $\mathbf{P}$ copies (while defending the existential) the choice of $\mathbf{O}$ (while resolving $R^{\rightarrow}(p)$ ) - namely $v$ - we are entitled to say that the left component of the playobject for the existential in the consequent is exactly the same in $B(x)$ as the left component of the existential occurring in the antecedent - i.e. $y=v(x): B(x)$.

\footnotetext{
${ }^{42}$ Extensionality can be also rendered, provided uniqueness of the function, for a dialogical reconstruction of the proof see Clerbout/Rahman (2015).

${ }^{43}$ However, as Jovanovic (2014) discusses, Hintikka tries to render its meaning via a non-constructive semantics based on IF-logic.

${ }^{44}$ See too Bell (2009, p. 203-204) who makes use of the notation of Tait (1994) that is very close to that of the instructions of the dialogical frame, provided they occur in the core of strategy - that is, when they occur in those expressions that constitute a winning strategy. Indeed, Tait's functions $\pi$ and $\pi^{\prime}$ corresponds to our left and right instructions - though we differentiate instructions for each logical constant adding an exponential to identify them. However, we do no have explicitly the function $\sigma$ of Tait, though the result of the substitution of an instruction with a pair of embedded instructions - what we call it's resolution - will yield the pair of its components.
} 
- Now, since in the antecedent $y$ in $C(x, y)$ is of type $B(x)$, for any $x: A$, and since, as already mentioned, $y$ is equal to $v(x)$ in $B(x)$, then it follows that $C(x, y)$ in the antecedent is, for any $x: A$, intensionally equal to $C(x, v(x))$ in the type set. More generally, and independently of $\mathbf{O}$ 's particular choice for the play-object for the antecedent, and independently of $\mathbf{O}$ 's particular choice of $x, C(x$, $y$ ) and $C(x, f(x))$ are two equal sets (for any $x: A$ and for $y: B(x)$ ).

From the two last steps it follows that $\mathbf{P}$ can copy-cat the play-object for the antecedent into the play-object for the consequent. This is the idea underlying a winning strategy for the Proponent for the Axiom of Choice. Also, these play-objects for antecedent and consequent are the ones relevant for the demonstration: one can then say that they are proof-objects. We will only deploy the plays that have been extracted of the extensive tree of all the plays. These plays constitute the so-called core of the strategy (that is, of the dialogical proof), ${ }^{45}$ and they are triggered by the Opponent's options at move 9 when challenging the existential posited by the Proponent at move 8 . Since O's repetition rank is 1 , she cannot perform both challenges within one and the same play, hence the distinction between the following two plays. The first play corresponds in the demonstration to the introduction of the universal in the consequent, under the assumption of the antecedent. The second play develops all the points of the informal demonstration described above:

First play: Opponent's $9^{\text {th }}$ move asks for the left play-object for the existential quantification on $f$

\begin{tabular}{|c|c|c|c|c|c|}
\hline \multicolumn{3}{|c|}{$\mathbf{O}$} & \multicolumn{3}{|c|}{$\mathbf{P}$} \\
\hline & $\begin{array}{c}\mathrm{H} 1: C(x, y): \operatorname{set}(x: A, y: \\
B(x)) \\
\mathrm{H} 2: B(x): \operatorname{set}(x: A)\end{array}$ & & & $\begin{array}{c}p:(\forall x: A)(\exists y: B(x)) C(x, y) \rightarrow(\exists f:(\forall x: A) B(x))(\forall x: A) \\
C(x, f(x))\end{array}$ & 0 \\
\hline 1 & $\mathrm{~m}:=1$ & & & $\mathrm{n}:=2$ & 2 \\
\hline 3 & $\begin{array}{c}L^{\rightarrow}(p):(\forall x: A)(\exists y: B(x)) \\
C(x, y)\end{array}$ & 0 & & $R^{\rightarrow}(p):(\exists f:(\forall x: A) B(x))(\forall x: A) C(x, f(x))$ & 6 \\
\hline 5 & $\begin{array}{c}v:(\forall x: A)(\exists y: B(x)) \\
C(x, y)\end{array}$ & & 3 & $L^{\rightarrow}(p) / ?$ & 4 \\
\hline 7 & $R^{\rightarrow}(p) / ?$ & 6 & & $(v, r):(\exists f:(\forall x: A) B(x))(\forall x: A) C(x, f(x))$ & 8 \\
\hline 9 & $?_{L}$ & 8 & & $L^{\exists}(v, r):(\forall x: A) B(x)$ & 10 \\
\hline 11 & $L^{\exists}(v, r) / ?$ & 10 & & $v:(\forall x: A) B(x)$ & 12 \\
\hline 13 & $L^{\forall}(v): A$ & 12 & & $R^{\forall}(v): B(w)$ & 26 \\
\hline 15 & $w: A$ & & 13 & $L^{\forall}(v): / ?$ & 14 \\
\hline 19 & $R^{\forall}(v):(\exists y: B(w)) C(w, y)$ & & 5 & $L^{\forall}(v): A$ & 16 \\
\hline 17 & $L^{\forall}(v) / ?$ & 16 & & $w: A$ & 18 \\
\hline 21 & $\left(t_{1}, t_{2}\right):(\exists y: B(w)) C(w, y)$ & & 19 & $R^{\forall}(v) / ?$ & 20 \\
\hline 23 & $L^{\exists}\left(\left(t_{1}, t_{2}\right): B(w)\right.$ & & 21 & $?_{L}$ & 22 \\
\hline 25 & $t_{1}: B(w)$ & & 23 & $L^{\exists}\left(t_{1}, t_{2}\right) / ?$ & 24 \\
\hline 27 & $R^{\forall}(v) / ?$ & 26 & & $t_{1}: B(w)$ & 28 \\
\hline
\end{tabular}

\footnotetext{
${ }^{45}$ For the process of their extraction and for the proof that these plays render the corresponding CTT demonstration see Clerbout/Rahman (2015).
} 


\section{Description:}

Move 3: After setting the thesis and establishing the repetition ranks $\mathbf{O}$ launches an attack on material implication.

Move 4: $\mathbf{P}$ launches a counterattack and asks for the play-object that corresponds to $L^{\rightarrow}(p)$.

Moves 5, 6: $\mathbf{O}$ responds to the challenge of 4 . $\mathbf{P}$ posits the right component of the material implication.

Moves 7, 8: $\mathbf{O}$ asks for the play-object that corresponds to $R^{\rightarrow}(p)$. $\mathbf{P}$ responds to the challenge by choosing the pair $(v, r)$ where $v$ is the play-object chosen to substitute the variable $f$ and $r$ the playobject for the right component of the existential.

Move 9: $\mathbf{O}$ has here the choice to ask for the left or the right component of the existential. The present play describes the development of the play triggered by the left choice.

Moves 10-26: follow from a straightforward application of the dialogical rules. Move 26 is an answer to move 13, which $\mathbf{P}$ makes after he gathered the information the application of the copy-cat method (enclosed in the formal rule) requires.

Move 27-28: $\mathbf{O}$ asks for the play-object that corresponds to the instruction posited by $\mathbf{P}$ at move 26 and $\mathbf{P}$ answers and wins by applying copy-cat to $\mathbf{O}$ 's move 25 . Notice that 28 this is not a case of function substitution: it is simply the resolution of an instruction.

Second play: Opponent's $9^{\text {th }}$ move asks for the right play-object for the existential quantification on $f$

\begin{tabular}{|c|c|c|c|c|c|}
\hline \multicolumn{3}{|c|}{$\mathbf{O}$} & \multicolumn{3}{|c|}{$\mathbf{P}$} \\
\hline & $\begin{array}{c}\mathrm{H} 1: C(x, y): \operatorname{set}(x: A, y: \\
B(x)) \\
\mathrm{H} 2: B(x): \operatorname{set}(x: A)\end{array}$ & & & $\begin{array}{c}p:(\forall x: A)(\exists y: B(x)) C(x, y) \rightarrow(\exists f:(\forall x: A) B(x)) \\
(\forall x: A) C(x, f(x))\end{array}$ & 0 \\
\hline 1 & $\mathrm{~m}:=1$ & & & $n:=2$ & 2 \\
\hline 3 & $\begin{array}{c}L^{\rightarrow}(p):(\forall x: A)(\exists y: B(x)) \\
C(x, y)\end{array}$ & 0 & & $R^{\rightarrow}(p):(\exists f:(\forall x: A) B(x))(\forall x: A) C(x, f(x))$ & 6 \\
\hline 5 & $v:(\forall x: A)(\exists y: B(x)) C(x, y)$ & & 3 & $L^{\rightarrow}(p) / ?$ & 4 \\
\hline 7 & $R^{\rightarrow}(p) / ?$ & 6 & & $(v, r):(\exists f:(\forall x: A) B(x))(\forall x: A) C(x, f(x))$ & 8 \\
\hline 9 & $?_{R}$ & 8 & & $R^{\exists}(v, r):(\forall x: A) C\left(x, L^{\exists}(v, r)(x)\right.$ & 10 \\
\hline 11 & $L^{\exists}(v, r) / ?$ & 10 & & $R^{\exists}(v, r):(\forall x: A) C(x, v(x))$ & 12 \\
\hline 13 & $R^{\exists}(v, r) / ?$ & 12 & & $r:(\forall x: A) C(x, v(x))$ & 14 \\
\hline 15 & $L^{\forall}(r): A$ & 14 & & $R^{\forall}(r): C(x, v(w))$ & 32 \\
\hline 17 & $w: A$ & & 15 & $L^{\forall}(r): / ?$ & 16 \\
\hline 21 & $R^{\forall}(v):(\exists y: B(w)) C(w, y)$ & & 5 & $L^{\forall}(v): A$ & 18 \\
\hline 19 & $L^{\forall}(v) / ?$ & 18 & & $w: A$ & 20 \\
\hline 23 & $\left(t_{1}, t_{2}\right):(\exists y: B(w)) C(x, y)$ & & 21 & $R^{\forall}(v) / ?$ & 22 \\
\hline 25 & $L^{\exists}\left(\left(t_{1}, t_{2}\right): B(w)\right.$ & & 23 & $?_{L}$ & 24 \\
\hline 27 & $t_{1}: B(w)$ & & 25 & $L^{\exists}\left(t_{1}, t_{2}\right) / ?$ & 26 \\
\hline 29 & $R^{\exists}\left(t_{1}, t_{2}\right): C\left(w, t_{1}\right)$ & & 23 & $R_{?}$ & 28 \\
\hline 31 & $t_{2}: C\left(w, t_{1}\right)$ & & 29 & $R^{\exists}\left(t_{1}, t_{2}\right) / ?$ & 30 \\
\hline 33 & $R^{\forall}(r) / ?$ & 32 & & $t_{2}: C(w, v(w))$ & 34 \\
\hline 35 & $v(w) / ?$ & 34 & & $\begin{array}{c}t_{2}: C\left(w, t_{1}\right) \\
<C\left(w, t_{1}\right)=C\left(w, t_{1} / v(w)\right): \text { set }>\end{array}$ & 42 \\
\hline 41 & $C\left(w, t_{1)}=C\left(w, t_{1} / v(w)\right): \operatorname{set}\right.$ & & H1? subst & $v(w)=t_{1}: B(w)$ & 36 \\
\hline 37 & $v(w)=t_{1}: B(w) ?$ & 36 & & $\operatorname{sic}(39)$ & 40 \\
\hline 39 & $v(w)=t_{1}: B(w)$ & & $\begin{array}{l}5,18 \\
21,25\end{array}$ & $?_{\text {П-eq. }}$ & 38 \\
\hline
\end{tabular}




\begin{abstract}
Description:
Move 9: Until move 9 this play is the same as the previous one. In the present play, in move 9 the Opponent chooses to ask for the right-hand side of the existential posited by $\mathbf{P}$ at 8 .

Moves 10-34: the Proponent substitutes the variable $f$ by the instruction correspondent to the lefthand component of the existential, i.e., $L^{\exists}(v, r)$. By this $\mathbf{P}$ accounts for the dependence of the righthand part on the left-hand component. The point is that the local meaning of the existential requires this dependence of the right component to the left component even if in this play the Opponent, due to the restriction on rank 1, can ask only for the right-hand part.

The conceptually interesting moves start with 35 , where the Opponent asks $\mathbf{P}$ to substitute the function. As already pointed out, in order to respond to 35 the Opponent's move 31 is not enough. Indeed the Proponent needs also to posit $C\left(w, t_{1}\right)=C\left(w, t_{1} / v(w)\right)$ : set. $\mathbf{P}$ forces $\mathbf{O}$ to concede this equality (41), on the basis of the substitutions $w / x$ and $t_{1} / y$ on H1 (we implemented the substitution directly in the answer of $\mathbf{O}$ ) given the $\Pi$-equality $v(w)=t_{l}$ in $B(w)(36)$, and given that this $\Pi$-equality yields the required set equality. Moreover, P's posit of the $\Pi$-equality (36) is established and defended by moves 38-40.
\end{abstract}

\title{
II.2 The core of the winning strategy
}

The core of the winning strategy in the dialogical game for the Axiom of Choice consists of the two plays we have just described, written in a linear way and with a ramification when the Opponent can choose between asking for the left and asking for the left at her move 9.

This results in the tree-like structure given on next page. In order to identify the dialogical source of each move we make use of $[? n]$ to indicate the attacked line and and $[\mathrm{m}]$ to indicate the challenge of player $\mathbf{X}$ that triggered the posited defence of $\mathbf{Y}$ 
O H1: $C(x, y): \operatorname{set}(x: A, y: B(x))$

O H2: $B(x): \operatorname{set}(x: A)$

0. P $p:(\forall x: A)(\exists y: B(x)) C(x, y) \rightarrow(\exists f:(\forall x: A) B(x))(\forall x: A) C(x, f(x))$

$1 \mathbf{O} \mathrm{n}:=1$

2. $\mathbf{P} \mathrm{m}:=1$

$3 \mathbf{O} L^{\rightarrow}(p):(\forall x: A)(\exists y: B(x)) C(x, y)$

[? 0]

$4 \mathbf{P} L^{\rightarrow}(p) /$ ? [? 3]

$5 \mathbf{O} v:(\forall x: A)(\exists y: B(x)) C(x, y) \quad$ [4]

$6 \mathbf{P} R^{\rightarrow}(p):(\exists f:(\forall x: A) B(x))(\forall x: A) C(x, f(x))$

$7 \mathbf{O} R^{\rightarrow}(p) / ? \quad[? 6]$

$8 \mathbf{P}(v, r):(\exists f:(\forall x: A) B(x))(\forall x: A) C(x, f(x)) \quad$ [7]

$90 ?_{L} \quad[? 8]$

$10 \mathbf{P} L^{\exists}(v, r):(\forall x: A) B(x)[9]$

$11 \mathbf{O} L^{\exists}(v, r) / ?$ [? 10]

$12 \mathbf{P} v:(\forall x: A) B(x)[11]$

$13 \mathbf{O} L^{\forall}(v): A[?$ 12]

$14 \mathbf{P} L^{\forall}(v):$ /? [? 13]

$15 \mathbf{O} w: A$ [ 14]

$16 \mathbf{P} L^{\forall}(v): A[? 5]$

$17 \mathbf{O} L^{\forall}(v) / ?[? 16]$

$18 \mathbf{P} w: A$ [ 17]

19 O $R^{\forall}(v):(\exists y: B(w)) C(w, y)[16]$

$20 \mathbf{P} R^{\forall}(v) / ?[?$ ? 19]

$21 \mathbf{O}\left(t_{1}, t_{2}\right):(\exists y: B(w)) C(w, y)[20]$

$22 \mathbf{P} L_{?}$ [? 21]

$23 \bigcirc L^{\exists}\left(\left(t_{1}, t_{2}\right) B(w)[22]\right.$

$24 \mathbf{P} L^{\exists}\left(t_{1}, t_{2}\right) /$ ? [? 23]

$25 \mathbf{O} t_{1}: B(w)$ [24]

$26 \mathbf{P} R^{\forall}(v): B(w)[13]$

$27 \mathbf{O} R^{\forall}(v) / ? \quad[? 26]$

$28 \mathbf{P} t_{1}: B(w)[27]$
9 O ? $\left.?_{R}[?] 8\right]$

$10 \mathbf{P} R^{\exists}(v, r):(\forall x: A) C\left(x, L^{\exists}(v, r)(x)[9]\right.$

$11 \mathbf{O} L^{\exists}(v, r) / ?$ [? 10]

$12 \mathbf{P} R^{\exists}(v, r):(\forall x: A) C(x, v(x))[11]$

$13 \bigcirc R^{\exists}(v, r) / ?$ [? 12]

$14 \mathbf{P} r:(\forall x: A) C(x, v(x))$ [ 13]

$15 \mathbf{O} L^{\forall}(r): A$ [? 14]

$16 \mathbf{P} L^{\forall}(r):$ /? [? 15]

$17 \mathbf{O} w: A[16]$

$18 \mathbf{P} L^{\forall}(v): A$ [? 5]

$19 \mathbf{O} L^{\forall}(v) / ?[? 18]$

$20 \mathbf{P} w: A$ [ 19]

$21 \mathbf{O} R^{\forall}(v):(\exists y: B(w)) C(w, y)[18]$

$22 \mathbf{P} R^{\forall}(v) /$ ? [? 21]

$23 \mathbf{O}\left(t_{1}, t_{2}\right):(\exists y: B(w)) C(w, y)[22]$

$24 \mathbf{P} ?_{L}[? 23]$

$25 \mathbf{O} L^{\exists}\left(\left(t_{1}, t_{2}\right): B(w)[24]\right.$

$26 \mathbf{P} L^{\exists}\left(t_{1}, t_{2}\right) / ?$ [? 25]

27 O $t_{1}: B(w)[26]$

$28 \mathbf{P} ?_{R}[?$ 23]

29 O $R^{\exists}\left(t_{1}, t_{2}\right): C\left(w, t_{1}\right)[28]$

$30 \mathbf{P} R^{\exists}\left(t_{1}, t_{2}\right) /$ ? [? 29]

$31 \mathbf{O} t_{2}: C\left(w, t_{1}\right)[30]$

$32 \mathbf{P} R^{\forall}(r): C(w, v(w))[15]$

$33 \mathbf{O} R^{\forall}(r) /$ ? [? 32]

$34 \mathbf{P} t_{2}: C(w, v(w))[33]$

35 O $v(w) / ?$ [? 34]

$36 \mathbf{P} v(w)=t_{1}: B(w)[? \mathrm{H} 1]$

$37 \mathbf{O} v(w)=t_{1} ?[? 36]$

$38 \mathbf{P}$ ? П-еq $[$ ? , 5, 18, 21, 25]

$39 \mathbf{O} v(w)=t_{1}: B(w)[38]$

$40 \mathbf{P}$ sic [39]

41 O $C\left(w, t_{l}\right)=C\left(w, t_{1} / v(w)\right): \operatorname{set}[36]$

$42 \mathbf{P} t_{2}: C\left(w, t_{1}\right)<C\left(w, t_{1}\right)=C\left(w, t_{1} / v(w)\right):$ set $>[35]$ 


\section{II.3 Final remarks}

According to Hintikka, the following formulation of the Axiom of Choice,

$$
\forall x \exists y C(x, y) \rightarrow \exists f \forall x C(x, f(x))
$$

(where it is left implicit that $\forall x$ quantifies over, say the set $A$, $\exists y$ quantifies over, say the set $B$, and $\exists f$, over the set $(\forall x: A) B x$ )

is perfectly acceptable for the constructivists. Let us recall, that the GTS reading of its truth amounts to the existence of winning strategy for Eloise in a game $\mathrm{G}(\forall x \exists y C(x, y))$. The latter amounts to finding a "witness individual" $y$ dependent upon $x$, such that $C(x, y)$ is true - notice how close this formulation is to Martin-Löfs "informal" description of the proof of the axiom. In other words, the existence of a winning strategy for that game provides a proof that the proposition $S(x, y)$ is true in the model (Hintikka, 1996a, ch 2). Hintikka claims that it is the GTS reading that makes the Axiom of Choice acceptable for the constructivists:

Moreover, the rules of semantical games should likewise be acceptable to a constructivist. In order to verify an existential sentence $\exists x S[x]$ I have to find an individual $b$ such that I can (win in the game played with) S[b]. What could be a more constructivistic requirement than that? Likewise, in the verification game $G\left(S_{1} v S_{2}\right)$ connected with a disjunction $\left(S_{1} v S_{2}\right)$, the verifier must choose $S_{1}$ or $S_{2}$ such that the game connected with it (i.e., $G\left(S_{1}\right)$ or $G\left(S_{2}\right)$ ) can be won by the verifier. Again, there does not seem to be anything here to alienate a constructivist. (Hintikka, 1996a, p. 212)

As mentioned above Hintikka is right, this is acceptable for the constructivists, but the reason is the underlying intensionality of the choice function and this assumes an underlying intuitionistic and not a classical logic as Hintikka was aiming at. An alternative option is to formulate the constructivist version of Axiom of Choice in an IFsetting. In such a setting the rejection of the constructivists is rendered as the rejection of the de re occurrence of the choice function in the consequent. The price to pay is known: the resulting formal system is not axiomatizable. This is a too high price, given that its truth can be made evident with the means of CTT. ${ }^{46}$ Moreover, the IF-reconstruction of the version of the Axiom of Choice rejected by the constructivist is not equivalent to the third-excluded. Hence, the IF-reconstruction is really changing the subject at stake.

Hintikka's intention was to offer a realist foundation of mathematics on a firstorder level in a way that all classical mathematics can be comprised and that it can still be acceptable for a constructivist. As pointed out by Göran Sundhom (2013a), under constructivist reading IF logic is granted to be a first-order logic, but in that case not all of the classical mathematics can be saved. However, as we think we have shown in this section, a game-theoretical interpretation that meets the epistemic requirements of the constructivists is possible, but this produces a dialogical version with an antirealist approach to meaning rather than a GTS interpretation with an underlying model of formal semantics. In fact, the point of Hintikka, is still a valuable one, the winning strategy of a universal quantifier is a function, such that, if there is an existential embedded in the

${ }^{46}$ Cf. Jovanovic (2014). 
universal expression; the verifier will make his choices (for the existential) dependent upon the ones of the falsifier. This is what the constructive reading is about. Moreover, Hintikka's point can be carried out precisely in a language that allows those dependent proof-objects (i.e. functions) to be expressed at the object language level of first-order logic: the functions are in fact nothing more than the truth-makers (proofobjects/winning-strategies) of the corresponding first-order expressions. This point is crucial for the understanding of anaphora.

\section{GTS and Dialogical Logic on Anaphora}

Hintikka's and associates' work on anaphora, based on Game-Theoretical semantics (GTS), constitutes a landmark in the field and it triggered many valuable contributions and discussions. The landmark-setting of Sundholm (1986) and the further developments of Ranta (1994) show that CTT has the means to provide a precise analysis of anaphoric expressions. In this section we will compare the GTS approach to anaphora with that of the dialogical approach. It is our opinion that GTS approach provides - from viewpoint of its use in natural language, an understanding of anaphora that is very close to actual linguistic practice: recall that anaphora is one of the main structures of conversational contexts. Thus, a semantics based on interaction seems to be indeed the most suitable approach. However, according to our view, the extension of the dialogical framework discussed in the precedent sections contains both the contentual (first-order) features of CTT placed at the object language level and the interactive aspects of GTS.

\section{III.1 The GTS approach to anaphora}

The issue is to find a satisfying semantic analysis of anaphoric expressions occurring in sentences such as:

1. If Michael smiles he is happy.

2. If a man smiles he is happy.

3. Every man that smiles is happy;

and of more problematic examples such as the famous donkey sentence:

4. Every man who owns a donkey beats it.

Texts such as

5. Nick stood up. He was all right. He looked up at the lights of the caboose going out of sight around the curve.

Conversations such as 


\section{Bernadette drinks her coffee with 5 cubes of sugar. Bernadette who? Ah, the}

Ivorian doctorate student of Shahid Rahman. She will get sick eventually.

The first sentence apparently is not problematic. The pronoun "he" has a strict interpretation (Michael), so it can be treated as a singular term. The issue is to provide a satisfying semantic analysis of pronouns "he" or "it" which becomes more challenging when there is interplay between pronouns and indefinites such as in the other cases.

Since the main aim of the present paper is to motivate studies on the interface between games and CTT we will not really delve into all the fine subtleties of all the different anaphora-cases but rather centre our attention to the general case and then the example of the donkey sentence. Moreover, since; as mentioned above, we are convinced that the interaction aspect stressed by Hintikka's analysis is crucial to the understanding of anaphora we will start with a brief overview of Hintikka's et alii approach. ${ }^{47}$

According to Hintikka's analysis, if a quantifier is understood as a logical expression then we are speaking of its priority scope in relation to the rest of the sentence, but if it is understood as the antecedent for anaphoric pronoun that appears in the rest of the sentence then we are dealing with its binding scope. It is a pity, from Hintikka's point of view, that those two different moments are expressed by the same syntactic expression. At first glance, it is appealing to interpret anaphoric pronouns as variables available for quantification. But Hintikka contests this view:

[...] they do not behave like bound variables. An anaphoric pronoun does not receive its reference by sharing it with the quantifier phrase that is its "head", any more than a definite description does. An anaphoric pronoun is assigned a reference in a semantical game through a strategic choice of a value from the choice set by one of the players. When the member of the choice set whose selection is a part of the winning strategy of the player in question happens to be introduced to the choice set by a quantifier phrase, that phrase could perhaps be called the head of the pronoun. But, as was pointed out, the origin of the members of the choice set does not matter at all in the semantical rules for anaphoric pronouns. (Hintikka, 1997, p. 530)

What Hintikka seems to be aiming at is to stress the cases where the relevant meaning-relation between a quantifier and the quantified expression is a relation of dependence rather than a compositional one, and that such dependences should be understood as interaction. This was one of the main motivation for a GTS-approach to anaphora and it was further developed by Sandu and his associates (Sandu 1997, Sandu/Jacot 2012). In other words, the main point of anaphora is dependence, dependence is interaction, and thus a semantics of interaction is required. Let us see the latter point before we study its applications.

\section{III.1.1 GTS}

According to GTS, meaning is obtained through the interaction of two players, Verifier and Falsifier, ${ }^{48}$ in a semantic game. The game starts from the whole formula and descending to the atomic formulas, the truth of which is checked in the model - in other words, the attribution of meaning goes exactly the inverse way of standard Tarksi-style semantics which proceeds "from inside out". This "outside-in" approach seems to be

\footnotetext{
${ }^{47}$ Already in 1985 Hintikka and Kulas used GTS in order to provide semantics of definite descriptions.

${ }^{48}$ Sometimes called Myself and Nature.
} 
much more promising in the treatment of meaning and that is the feature that GTS shares with the dialogical approach we will discuss in III.2.

The game is defined as follows:

\section{-Definition:}

Let Eloise and Abelard be the players in a game. Eloise is the initial verifier, trying to defend the sentence at stake and Abelard is the initial falsifier, trying to deny it.

A semantic game $G(\varphi)$ for the sentence $\varphi$ begins with $\varphi$. The game is played in the model $\mathbb{M}$ with a given language L. Through various stages of the game, players will consider either the sentence $\varphi$ or other sentence $\varphi$ ' obtained from $\varphi$ during the development of the game. The game is played with well-defined rules.

$\mathrm{R} \vee$ - disjunction-rule: $G\left(\varphi_{1} \vee \varphi_{2}\right)$ starts by the choice of the player who has (in $G$ ) the role of verifier, for $\varphi_{\mathrm{i}}(\mathrm{i}=1$ or 2$)$. The game continues as $G\left(\varphi_{i}\right)$.

$\mathrm{R} \wedge$ - conjunction-rule: $G\left(\varphi_{1} \wedge \varphi_{2}\right)$ starts by the choice of the player who has (in $G$ ) the role of falsifier, for $\varphi_{\mathrm{i}}(\mathrm{i}=1$ or 2$)$. The game continues as $G\left(\varphi_{i}\right)$.

$\mathrm{R} \exists$ - rule: $G(\exists x S x)$ starts by the choice of the player who has (in $G)$ the role of verifier, of one member from the domain of $\mathbb{M}$ for $x$. If the name of the individual is $a$, the game is played as $G(S a)$.

$\mathrm{R} \forall$ - rule: $G(\forall x S x)$ starts by the choice of the player who has (in $G$ ) the role of falsifier, of one member from the domain of $\mathbb{M}$ for $x$. If the individual is $a$, the game is played as $G(S a)$.

$\mathrm{R} \neg$ - rule: $G(\neg \varphi)$ is played the same as $G(\varphi)$ except that players change their roles.

$\mathrm{R}$ - atomic-rule for the atomic sentences: if $A$ is an atomic sentence that is true, the verifier wins. If the sentence is false the falsifier wins.

Each application of the rules eliminates one logical constant, so that in a finite number of steps eventually the rule for atomic sentences must be applied. Truth of an atomic sentence is determined by the model $\mathbb{M}$ with respect to which $G(\varphi)$ is played. In other words, the game $G$ assumes the interpretation of all non-logical constants in the model $\mathbb{M}$, and it provides the (model-theoretical) meaning of the primitive symbols of a given interpreted first-order language.

Finally, here are the truth and falsity conditions for arbitrary formulae:

-Definition:

a) $\varphi$ is true in model $\mathbb{M}\left(\mathbb{M} F_{t} \varphi\right)$ if and only if there is a winning strategy for Eloise in the game $G(\varphi)$ played in $\mathbb{M}$.

b) $\varphi$ is false in model $\mathbb{M}\left(\left.\mathbb{M}\right|_{f} \varphi\right)$ if and only if there is a winning strategy for Abelard in the game $G(\varphi)$ played in $\mathbb{M}$.

\section{III.1.2 GTS, Anaphora and Branching Quantifiers}

In the GTS frame, strategies of players that are introduced on the semantic level are Skolem functions that tell a player which disjunct/ conjunct or which individual in the model to choose every time it is her turn to play. Given the prenex normal form of a formula, we obtain its Skolem form by replacing systematically every existential quantifier by an appropriate Skolem function the argument of which is a variable bound by a universal quantifier in the scope of which that existential quantifier lays. Hintikka's main idea is that a Skolemization of the strategies yields a correct analysis of the anaphora. Sandu/Jacot (2012) added the further step of introducing the skolemization in the object language level by means of Skolem terms. 
Let us see how this works in the case of the donkey sentence. The analysis starts with the GTS approach of the following universal:

Every man owns a donkey.

In a game played for this sentence it is the falsifier who first chooses an individual that satisfies the predicate of being a man. Then it is on the verifier to find a donkey owned by that individual in order to win the game. This game can be represented as a tree with branches that shows all possible outcomes of the game (for any individual chosen by falsifier). The strategy of the verifier is then a function $f$ that for any individual $a$, chosen by falsifier gives as a result $f(a)$, that is a donkey owned by a. The sentence given above is then formalised as

$$
\forall x(\operatorname{Man}(x) \rightarrow \operatorname{Donkey}(f(x)) \wedge O w n(x, f(x)))
$$

We can now turn to the anaphoric pronoun in the sentence 4. A solution for the problematic anaphora is found with help of a Skolem term. The pronoun "it" is a copy of a Skolem term in the antecedent. The formalisation of 4 thus is:

$$
\forall x(((\operatorname{Man}(x) \wedge \text { Donkey }(f(x))) \wedge \text { Own }(x, f(x))) \rightarrow \text { Beats }(x, f(x))) .
$$

Sandu and Jacot (2012, p. 620) claim that Skolem terms are very useful semantic tools for anaphora because they keep track of the entire history of a play of a game. All the variables bound by quantifiers superior to the indefinites are found as the arguments of each Skolem term. This solution combines at once the quasi-referential view on quantifiers, which is appealing when an anaphoric pronoun appears in a sentence, and the idea of semantic dependency, which is needed both when there is a nesting of indefinites and where there is an interplay of indefinites with quantifiers.

Moreover, this, method can be extended to more complicated cases of dependence such as the ones of Henkin's branching quantifiers, that were before analysed by combining GTS with Independence friendly first-order logic (for short: IF). ${ }^{49}$ Indeed; the IF-analysis of the case of branching quantifiers yields:

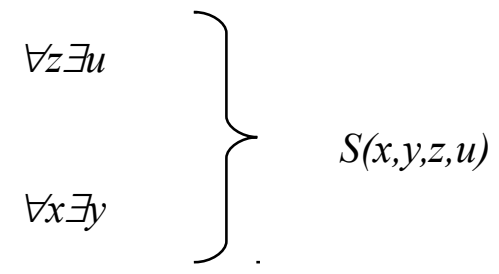

cannot be expressed with one (linearly disposed) sentence of classical first-order logic. However this can be done in IF in the following way:

$$
\forall x \forall z(\exists y / \forall z)(\exists u / \forall x) S(x, y, z, u)
$$

\footnotetext{
${ }^{49}$ IF first-order logic is an extension of first-order logic, involving a specific syntactic device ' $/$ ' (slash, independence indicator), which has at the object language level the same effect as the meta-level modifier 'but does not depend on'. IF was introduced by Jaakko Hintikka and Gabriel Sandu in their article 'Informational Independence as a Semantical Phenomenon' (1989); other early sources are Hintikka's booklet Defining Truth, the Whole Truth, and Nothing but the Truth (1997) and Sandu's Ph.D. thesis (1991).
} 
where the slashes indicates that $\exists y(\exists u)$ is independent of $\forall z(\forall x)$.

In some cases, the slash does not contribute to anything that could not be expressed without it, but in others it allows to express structural features that we would not otherwise be able to express in standard first-order logic. Walkoe showed that the expressive power of formulas with branching quantifiers is precisely that of existential second-order logic (Walkoe, 1970). ${ }^{50}$ Independently, Walkoe and Enderton also showed that every existential second-order sentence $\sum_{1}^{1}$ is equivalent to second-order truth or falsity condition of an IF sentence. (Walkoe 1970, Enderton 1970). Thus, IF logic captures exactly the expressive power of Henkin's branching quantifiers, though according to Hintikka IF is first-order. ${ }^{51}$

A classic example of a natural language sentence that involves branching quantifiers from (Hintikka 1973, p. 344) is:

\section{Some relative of each villager and some relative of each townsman hate each} other.

If we formulate this in the new Skolem-terms-frame proposed by Sandu and Jacot (2012) we obtain:

$$
\begin{aligned}
& \forall x \forall z((\operatorname{Villager}(x) \wedge \text { Townsman }(z)) \rightarrow(\text { Relative }(x, f(x)) \wedge \text { Relative }(z, g(z)) \wedge \\
& \text { Hate }(f(x), g(z))))
\end{aligned}
$$

Or quantifying over the functions:

$$
\begin{aligned}
& \exists f \exists g \forall x \forall z((\text { Villager }(x) \wedge \text { Townsman }(z)) \rightarrow(\text { Relative }(x, f(x)) \wedge \\
& \text { Relative }(z, g(z)) \wedge \text { Hate }(f(x), g(z))))
\end{aligned}
$$

According to Hintikka, IF allows us to take into account different patterns of dependency among logical expressions that can appear in a sentence, and it is thus more appropriate for the translation of natural languages than other approaches are. ${ }^{52}$ Moreover, all this can be done at the first-order level. Similar can be said of the functional approach.

Now, the first-order reading of the IF-formulation has been contested and the issue has not been settled yet. However, as already mentioned in the introduction and at

\footnotetext{
${ }^{50}$ Existential second-order logic is a fragment of second-order logic that consists of a formula in the form $\exists x_{1 \ldots} . \exists x_{n} \Psi$, where $\exists x_{1 \ldots} . \exists x_{n}$ are second-order quantifiers and $\Psi$ is a first-order formula.

${ }^{51}$ Feferman (2006) and Väänänen (2001) rose however the question whether IF logic is really first-order logic. Tulenheimo (2009) provides some elements to defend Hintikka's view. Curiously, Sundholm (2013a) shows that those dependences and independences that motivate Hintikka's introduction of IF can be formulated in CTT first-order logic.

${ }^{52}$ Strategies for players in a game for a given sentence are expressed by existential second-order sentences, usually noted as $\sum_{1}^{1}$. According to (Hintikka 1997, p. 523) "this second-order statement expresses the logical form of the given natural-language sentence. It is equivalent to an IF first-order sentence, which can also be considered as the translation of the given natural language sentence into logical notation.". The existential part of second-order logic exceeds in expressivity classical first-order logic, and since IF is equivalent to $\sum_{1}^{1}$, so does independent friendly logic (IFL).
} 
the end of the section on the Axiom of Choice, the point is that the simple move of substituting Skolem functions by proof-objects of the quantified propositions under consideration yields a straightforward first-order reading: the functions at stake are the truth-makers of the propositions involving quantifier dependences. Furthermore the dialogical approach contributes to the game-theoretical approach by providing the elementary constituents of which the dependent proof-objects are made of. Indeed the dialogical approach provides the method to build the dependent proof-objects underlying a suitable winning strategy. We undertake this task in the next section.

\section{III.2 The Dialogical Approach to Anaphora}

In what follows we will give a dialogical account of anaphora making use of CTT. We will argue that the GTS approach, that puts the accent on expressing dependence relation in terms of choices, resulting from interaction, is indeed a good way to deal with anaphora. However, our approach is closer to the recent Skolem-term framework developed by Sandu and Jacot than to the original analysis of Hintikka, though the dialogical framework can also deal with the more complicated cases involving branching quantifiers without making use of the formal system IF, and though, as mentioned above, we see Skolem-terms as the introduction into the object language level of dependentproof-objects constituted by play-objects.

From the more general point of view of philosophy of language the dialogical approach to anaphora seems to match with a weakened version of Brandom's view on the relations between anaphora and deixis. ${ }^{53}$ As pointed out by Penco (2005) the core of Brandom's strong claim for the conceptual priority of anaphora with respect to deixis according to Brandom (1994, pp. 464-468) deixis presupposes anaphora - is based on the observation that the capacity of pronouns to pick up a reference from an anaphoric antecedent is an essential condition of the capacity of other tokens (which can serve as such antecedents) to have references determined (Penco 2005, p. 182). And the argument is somehow plausible, if we are thinking of repeatable referential situations. In such situations it is the anaphoric structure that allows us to re-identify what has been referred to by an indexical - Brandom ascribes the role of anaphoric initiator to indexicals. On this view, anaphoric initiators can trigger anaphoric chains. More precisely, according to Brandom, as soon as we use demonstratives and indexicals, we are beginning to keep track of an object via a possible anaphoric chain - this is, according to Brandom, the very point of the use of demonstratives and indexicals. However, as discussed by Penco (2005, pp. 182-184) indexicals do not only have the role of anaphoric initiators: they also perform the function of connecting general beliefs with contexts. Also, an indexical is sometimes used only once, that is to say: without initiating an anaphoric chain. Therefore, it seems that a more prudent way to express the point reduces to the observation that deixis and anaphora should be thought together. Still, this does not change really the core of Brandom's remark that the function of indexicals and demonstratives is not exhausted in their unrepeatable occurrence.

\footnotetext{
${ }^{53}$ Though as discussed in the last paragraphs of the present section our analysis differs from the one of Brandom.
} 
Be that as it may, the dialogical approach to pronouns takes them in their anaphoric role. Furthermore, since the dialogical approach to anaphora is based on the CTT-framework, also the dependence upon a context can be thought as having an anaphoric structure. In fact, Ranta (1994, p 78) introduces pronominalisation rules for inference in a CTT-frame in order to make explicit dependence of anaphoric pronouns upon the context. ${ }^{54}$ But context is understood as the assumption that the picked object is of a given type (e.g. the assumption that $x$ is of type $A$ ). Thus the pronouns (and more generally the indexicals) dependence upon a context is understood as a reference to any object of appropriate type.

For example, Ranta's inferential rules for the pronoun he and she deploy the identity mapping on the set of man and she as identity mapping on the set of woman as resulting for the contextual dependence:

$$
\begin{gathered}
a: \text { man } \\
\text { he(a): man }
\end{gathered}
$$

And the rule of a substitution: ${ }^{55}$

a: $\operatorname{man}$

$$
h e(a)=a: \operatorname{man}
$$

It is important to notice that these rules do not really assume that an instance of the type given by the context is necessarily a constant expression, it could well be a variable (and then the context is in fact an open assumption). Moreover, it is possible to generalize the rule for embedded dependences, which renders Brandom's point on anaphoric chains. If we put all together the following inference rule described by Ranta (1994, p. 80) obtains:

$$
\begin{gathered}
a\left(x_{1}, \ldots, x_{n}\right): \operatorname{man}\left(x_{1}: A_{1}, \ldots, x_{n}: A_{n}\left(x_{1}, \ldots, x_{n-1}\right)\right) \\
h e\left(a\left(x_{1}, \ldots, x_{n}\right)\right): \operatorname{man}\left(x_{1}: A_{1}, \ldots, x_{n}: A_{n}\left(x_{1}, \ldots, x_{n-1}\right)\right), \\
h e\left(a\left(x_{1}, \ldots, x_{n}\right)\right)=a\left(x_{1}, \ldots, x_{n}\right): \operatorname{man}\left(x_{1}: A_{1}, \ldots, x_{n}: A_{n}\left(x_{1}, \ldots, x_{n-1}\right)\right)
\end{gathered}
$$

After the application of such rule (rules), it is possible to drop the argument $a$ and the bare pronoun he can be used - in the context $A$. This can be formulated by an additional "sugaring" rule such as

$$
h e(a)(a: A) \triangleleft h e
$$

In the dialogical framework, Ranta's pronominalization rules are understood as the intertwining of commitments and entitlements that characterizes Brandom's overall view on meaning:

\footnotetext{
${ }^{54}$ Context should be understood in the technical sense of CTT.

${ }^{55}$ In Ranta (1994, p. 78) those two rules (identity mapping and substitution) are united in one rule with two conclusions.
} 
If player $\mathbf{X}$ posits that $h e(a)$ : man, then his adversary can challenge this posit by asking him to show that $a$ is of the type man. Since we would like to include variables, the best is to make use again of instructions,

\begin{tabular}{|l|l|l|}
\hline Posit & Challenge & Defence \\
\hline X he $\left(\mathrm{I}^{\text {pron }}\right)$ : man & Y ? $^{\text {pron }}: \operatorname{man}$ & I I $^{\text {pron }}:$ man \\
\hline
\end{tabular}

The resolution of the instruction in $I^{\text {pron }}$ : man allows the defender to introduce explicitly an identity within the set man:

\begin{tabular}{|l|l|l|}
\hline Posit & Challenge & Defence \\
\hline $\mathbf{X} I^{\text {pron }}:$ man & $\mathbf{Y}_{\text {Ipron,man/?: }}$ & $\mathbf{X} h e\left(I^{\text {pron }}\right)=a:$ man \\
\hline
\end{tabular}

A third rule implements the argument-dropping rule mentioned above: If a player brought forward an identity of the form described above, then the challenger can use this identity to substitute, say, he(a) for a, wherever he(a) occurs. In this rule we assume that instruction $I^{\text {pron }}$ has already been substituted by a suitable play-object.

\begin{tabular}{|l|l|l|}
\hline Posit & Challenge & Defence \\
\hline $\mathbf{X} h e(a)=a:$ man & Y $?_{a / h e(a)}$ & $\mathbf{X} \varphi[a]$ \\
$\ldots$ & & \\
$\mathbf{X} \varphi[h e(a]$ & & \\
\hline
\end{tabular}

Because of the recursivity of the rules we will not write down explicitly the case of chains of dependences. Similar rules can be formulated for she. The case of it requires more care, since it's type might vary from context to context. Anyway this type-variation seems to apply to all pronouns (e.g. she : ship).

Let us come back to our example of the happy man:

If a man smiles he is happy.

The idea is that in order to obtain the interpretation for a pronoun he, we first formalize the first part "A man smiles" as:

( $\exists x:$ man) smiles $(x)$

and then we consider the sentence "he is happy" in the context

$z:\left(\exists x:\right.$ man) $\operatorname{smiles}(x){ }^{56}$

This analysis yields the following formalisation:

${ }^{56}$ In Ranta (1994, p. 79) the example is "If a man walks he talks". 
According to the rules given in section I, the left part of the universal given above consists of the set of all men that smile and the right part claims that an object chosen from that set is happy. The left part of universal is $\mathrm{L}^{\forall}(\mathrm{z})$, that is, the set of all men that smile: what the pronoun he does is to pick up one individual of the set of the smiley men (the set ( $\exists x$ : man) smiles $(x)$ ). Let us deploy a play that illustrates both the analysis and use of the rules. For the sake of simplicity we do not make use of the instruction $I^{\text {pron }}$ after all the pronoun has already picked an instruction. We will also ignore the moves involving the choice of repetition ranks:

\begin{tabular}{|c|c|c|c|c|c|}
\hline & $\mathbf{O}$ & & & P & \\
\hline & & & & $\begin{array}{l}(\forall z:(\exists x: \text { man }) \text { smiles }(x)) \text { happy }(\text { he } \\
\left.\left(L^{\forall}(z)\right)\right)\end{array}$ & 0 \\
\hline 1 & $L^{\forall}(z):(\exists x:$ man $)$ smiles $(x)$ & 0 & 1 & $R^{\forall}(z): \operatorname{happy}\left(h e\left(L^{\forall}(z)\right)\right)$ & 12 \\
\hline 3 & $a:($ Ex: man $)$ smiles $(x)$ & & & $L^{\forall}(z) / ?$ & 2 \\
\hline 5 & $L^{E}(a): \operatorname{man}$ & & 3 & $? L$ & 4 \\
\hline 7 & $R^{E}(a): \operatorname{smiles}\left(L^{E}(a)\right)$ & & 3 & $? R$ & 6 \\
\hline 9 & $a_{1}: \operatorname{man}$ & & 5 & $L^{E}(a) / ?$ & 8 \\
\hline 11 & $a_{2}: \operatorname{smiles}\left(a_{1}\right)$ & & 7 & $R^{E}(a) / ?$ & 10 \\
\hline 13 & $? L^{\forall}(z) / ? \ldots$ & 12 & & $R^{\forall}(z): \operatorname{happy}\left(\right.$ he $\left.\left(a_{1}\right)\right)$ & 14 \\
\hline 15 & ? a1:man & 14 & & $a_{1}: \operatorname{man}$ & 16 \\
\hline 17 & $I^{h e, m a n} / ?:$ & 16 & & $R^{\forall}(z): \operatorname{happy}\left(h e\left(a_{1}\right)=a_{1}\right)$ & 18 \\
\hline 19 & ?a/he(a) & 18 & & $R^{\forall}(z): \operatorname{happy}\left(a_{1}\right)$ & 20 \\
\hline 21 & $? R^{\forall}(z) /$ & 20 & & $\begin{array}{l}\mathbf{P} \text { loses unless he can force } \mathbf{O} \text { to concede that } \\
\text { there is a play-object } b \text { for happy }\left(a_{1}\right) \text {, such that } \\
\text { it allows } \mathbf{P} \text { to choose } b \text { for } R^{\forall}(z) \text { while } \\
\text { responding to the challenge of move } 21 \text { on } \\
\text { move } 20\end{array}$ & \\
\hline
\end{tabular}

Description:

Move 0: $\mathbf{P}$ states the thesis.

Move 1: $\mathbf{O}$ challenges the universal by positing an arbitrary man that smiles, that is $z$ : ( $\exists x:$ man) smiles $(x)$.

Move 2: $\mathbf{P}$ counterattacks by asking who that man is.

Move 3: $\mathbf{O}$ responds by choosing some play-object.

Move 4: Since $a$ is a play-object for an existential, it is constituted by two parts: $\mathbf{P}$ starts by asking for its left part.

Move 5: $\mathbf{O}$ answers that $L(a)$ is a man.

Move 6: $P$ challenges now the right part of the existential.

Move 7: $\mathbf{O}$ responds to the attack.

Move 8: $\mathbf{P}$ asks $\mathbf{O}$ to resolve the instruction occurring in the expression brought forward in move 5 Move 9: $\mathbf{O}$ responds by choosing $a_{1}$.

Move 10: $\mathbf{P}$ asks $\mathbf{O}$ to resolve the instruction occurring in the expression brought forward in move 7.

Move 11: $\mathrm{O}$ responds by choosing $a_{2}$.

Move 12: $\mathbf{P}$ answers now the challenge of move 1.

Move 13: $\mathbf{O}$ asks $\mathbf{P}$ to resolve the instruction $L^{\forall}(z)$ occurring in the expression brought forward in move 12 . 


\begin{abstract}
Move 14: $\mathbf{P}$ chooses $a_{1}$
Move 15: $\mathbf{O}$ challenges the pronoun $h e$.

Move 16: $\mathbf{P}$ can answer $a_{1}:$ man, since $\mathbf{O}$ conceded it before (namely in move 9).

Move 17: $\mathbf{O}$ forces $\mathbf{P}$ to bring forward the identity underlying the pronoun $h e$.

Move 18: $P$ brings forward the required identity.

Move 19: $\mathbf{O}$ forces $\mathbf{P}$ to use the identity brought forward in move 18 and apply it to drop the pronoun occurring in 14.

Move 20: $\mathbf{P}$ drops the pronoun and this yields $R^{\forall}(z): \operatorname{happy}\left(a_{1}\right)$.

Mover 21: $O$ asks to resolve the instruction occurring in the last move. Since it is an elementary expression and $\mathbf{O}$ did not concede it before $\mathbf{P}$ cannot has no move to play and loses the play.
\end{abstract}

$\mathbf{P}$ has a winning strategy if in a given context, $a_{l}$ is a man who smiles and is happy and that stands for every choice of man that $\mathbf{O}$ can make. Of course, this sentence is not valid. We could develop a material dialogue, by introducing concessions by $\mathbf{O}$ (premises) and thus check if there is or not a winning strategy. If there is, it amounts to an inference from materially given premisses. What we should not do is to design the material dialogue with help of a model (like Hintikka does) this would work against the epistemic frame underlying the present approach.

Let us now come to the analysis of the notorious example of the donkey sentence. We follow the analysis of Sundholm (1986) that constitutes a landmark in the application of CTT to natural language. In order to keep the focus in the interdependence of choices we skip the pronouns he and it and we replace them with the corresponding instructions already.

\title{
Every man who owns a donkey beats it.
}

As in the example above, first we formalize the first part of the sentence "man who owns a donkey" and we consider that sentence in the context, so we obtain

$$
z:(\exists x: \text { man) (ᄏy: donkey)(x owns y). }
$$

Since the existential is in fact the set $z$ is an element of, it is more convenient to use the set-separation notation

$$
z:\{x: \operatorname{man} \mid(\exists y: \text { donkey })(x \text { owns } y)\}
$$

We take the left part of $z$ to pick up a man (that owns a donkey). The right part of $z$ is the owned donkey (that is beaten). Putting all together yields

$$
p:(\forall z:\{x: \text { man } \mid(\exists y: \text { donkey })(x \text { owns } y)\})\left(L^{\{\ldots\}}(z) \text { beats } L^{\exists}\left(R^{\{\cdots\}}(z)\right)\right)
$$

Or more briefly

$$
p:(\forall z:\{x: M \mid(\exists y: D) O x y\}) B\left(L^{\{\cdots\}}(z), L^{\exists}\left(R^{\{\cdots\}}(z)\right)\right)
$$

Let us run the play but this time with a material dialogue - also here we ignore repetition ranks. Since it is a material dialogue, we know by the formation plays how the 
sets are composed and we also know that $m$ is man, $d$ a donkey and that $p$ ' is a playobject for the proposition that $m$ owns $d$. The point of the thesis is that $\mathbf{P}$ claims that if we know what has been already mentioned and given that very man who owns a donkey beats it, then man $m$ beats donkey $d$.

\begin{tabular}{|c|c|c|c|c|c|}
\hline & $\mathbf{O}$ & & & $\mathbf{P}$ & \\
\hline I & ! M : set & & & & \\
\hline II & ! D : set & & & & \\
\hline III & ! Oxy $: \operatorname{set}(x: M, y: D)$ & & & & \\
\hline IV & ! Bxy : set & & & & \\
\hline $\mathrm{V}$ & $\begin{array}{c}\text { ! p : }(\forall \mathrm{z}:\{\mathrm{x}: \mathrm{M} \mid(\exists \mathrm{y}: \mathrm{D}) \\
\mathrm{Oxy}\}) \mathrm{B}\left(\mathrm{L}^{\{\cdots\}}(\mathrm{z}), \mathrm{L}^{\exists}\left(\mathrm{R}^{\{\cdots\}}(\mathrm{z})\right)\right)\end{array}$ & & & & \\
\hline VI & $! \mathrm{m}: \mathrm{M}$ & & & & \\
\hline VII & $! d: D$ & & & & \\
\hline \multirow[t]{2}{*}{ VIII } & ! p' : Omd & & & & \\
\hline & & & & $! \mathrm{B}(\mathrm{m}, \mathrm{d})$ & 0 \\
\hline 1 & $n:=\ldots$ & & & $m:=\ldots$ & 2 \\
\hline 3 & ?play-object & $(0)$ & & $! \mathrm{q}: \mathrm{B}(\mathrm{m}, \mathrm{d})$ & 30 \\
\hline 25 & $! \mathrm{R}^{\forall}(\mathrm{p}): \mathrm{B}\left(\mathrm{L}^{\{\cdots\}}(\mathrm{z}), \mathrm{L}^{\exists}\left(\mathrm{R}^{\{\cdots\}}(\mathrm{z})\right)\right)$ & & $(\mathrm{V})$ & $! \mathrm{L}^{\forall}(\mathrm{p}):\{\mathrm{x}: \mathrm{M} \mid(\exists \mathrm{y}: \mathrm{D})$ Oxy $\}$ & 4 \\
\hline 5 & $\mathrm{~L}^{\forall}(\mathrm{p}) / ?$ & (4) & & ! z : $\{\mathrm{x}: \mathrm{M} \mid(\exists \mathrm{y}: \mathrm{D}) \mathrm{Oxy}\}$ & 6 \\
\hline 7 & $?_{\mathrm{L}}$ & $(6)$ & & $! \mathrm{L}^{\{\ldots\}}(\mathrm{z}): \mathrm{M}$ & 8 \\
\hline 9 & $\mathrm{~L}^{\{\cdots\}}(\mathrm{z}) / ?$ & $(8)$ & & $! \mathrm{m}: \mathrm{M}$ & 10 \\
\hline 11 & $?_{\mathrm{R}}$ & (6) & & $! \mathrm{R}^{\{\cdots\}}(\mathrm{z}):(\exists \mathrm{y}: \mathrm{D}) \mathrm{Omy}$ & 12 \\
\hline 13 & $\mathrm{R}^{\{\cdots\}}(\mathrm{z}) / ?$ & $(12)$ & & $\begin{array}{c}\text { ! }\left(\mathrm{L}^{\exists}\left(\mathrm{R}^{\{\ldots\}}(\mathrm{z})\right), \mathrm{R}^{\exists}\left(\mathrm{R}^{\{\ldots\}}(\mathrm{z})\right)\right):(\exists \mathrm{y}: \\
\mathrm{D}) \text { Omy }\end{array}$ & 14 \\
\hline 15 & $\mathrm{~L}^{\exists}\left(\mathrm{R}^{\{\ldots\}}(\mathrm{z})\right) / ?, \mathrm{R}^{\exists}\left(\mathrm{R}^{\{\ldots\}}(\mathrm{z})\right) / ?$ & $(14)$ & & $!\left(\mathrm{d}, \mathrm{p}^{\prime}\right):(\exists \mathrm{y}: \mathrm{D})$ Omy & 16 \\
\hline 17 & $?_{\mathrm{L}}$ & $(16)$ & & $! \mathrm{L}^{\exists}\left(\mathrm{d}, \mathrm{p}^{\prime}\right): \mathrm{D}$ & 18 \\
\hline 19 & $\mathrm{~L}^{\exists}\left(\mathrm{R}^{\{\ldots\}}(\mathrm{z})\right) / ?$ & $(18)$ & & ! d : D & 20 \\
\hline 21 & $?_{\mathrm{R}}$ & $(16)$ & & $! \mathrm{R}^{\exists}\left(\mathrm{d}, \mathrm{p}^{\prime}\right):$ Omd & 22 \\
\hline 23 & ${ }^{\mathrm{R}}\left(\mathrm{R}^{\{\cdots\}}(\mathrm{z})\right) / ?$ & $(22)$ & & ! $\mathrm{p}^{\prime}:$ Omd & 24 \\
\hline 27 & $! \mathrm{R}^{\forall}(\mathrm{p}): \mathrm{B}(\mathrm{m}, \mathrm{d})$ & & $(25)$ & $\mathrm{L}^{\{\cdots\}}(\mathrm{z}) / \mathrm{m}, \mathrm{L}^{\exists}\left(\mathrm{R}^{\{\ldots\}}(\mathrm{z})\right) / \mathrm{d}$ & 26 \\
\hline 29 & $! \mathrm{q}: \mathrm{B}(\mathrm{m}, \mathrm{d})$ & & (27) & $\mathrm{R}^{\forall}(\mathrm{p}) / ?$ & 28 \\
\hline
\end{tabular}




\section{Description:}

Moves I - VIII: These moves are O's initial concessions. Moves I- IV deal with the formation of expressions. After that the Opponent concedes the donkey sentence and atomic expressions related to the sets M, D and Oxy.

Moves 0- 3: The Proponent posits the thesis. The players choose their repetition ranks in moves 1 and 2. The actual value they choose does not really matter for the point we want to illustrate here, thus we simply assume that they are enough for this play and leave them unspecified. Now, when $\mathbf{P}$ posited the thesis he did not specified the play- objects so $\mathbf{O}$ asks for it in move 3 .

Move 4: $\mathbf{P}$ chooses to launch a counterattack by challenging the donkey sentence which $\mathbf{O}$ conceded at V. The rules allow the Proponent to answer directly to the Opponent's first challenge, but then he would not be able to win.

Move 5 - 24: The dialogue then proceeds in a straightforward way with respect to the rules introduced in sections I.2.2 and I.2.3. More precisely, this dialogue displays the case where $\mathbf{O}$ chooses to challenge P's posits as much as she can before answering P's challenge 4.

Notice that the Opponent cannot challenge the Proponent's atomic expressions posited at moves 10, 20 and 24: since $\mathbf{O}$ made the same posits in her initial concessions VI - VIII, the modified formal rule SR3 forbids her to challenge them.

Move 25: When there is nothing left for her to challenge, $\mathbf{O}$ comes back to the last unanswered challenge by $\mathbf{P}$ which was move 4 and makes the relevant defence according to the particle rule for universal quantification.

Moves 26 - 27: The resolution for instructions $L^{\{\ldots\}}(z)$ and $L^{\exists}\left(R^{\{\cdots\}}(z)\right)$ has been carried out during the dialogue with moves 9-10 and 23-24. Thus the Proponent can use the established substitutions to challenge move 25 according to the structural rule SR4.2. The Opponent defends by performing the requested substitutions.

Moves 28 - 30: The Proponent then asks the play-object for which the instruction $R^{\forall}(z)$ stands. When she answers, the Opponent posits exactly what $\mathbf{P}$ needs to defend against $\mathbf{O}$ 's challenge 3. Notice that at this point this is the last unanswered challenge by $\mathbf{O}$, therefore $\mathbf{P}$ is allowed to answer it in accordance to the structural rule SR1 $i$. He does so with his move 30.

Since $\mathbf{O}$ made the same posit, the rule SR3 forbids her to challenge it. She then has no further possible move, and the Proponent wins this dialogue.

What about the more difficult examples involving branching quantifiers?. As shown by Sundholm (2013a) a CTT-analysis yields ${ }^{57}$

$(\exists f \in(\Pi x \in D) D)(\exists g \in(\Pi x \in D) D)(\forall x \in D)(\forall u \in D) A[a p(f, x) / y, a p(g, u) / v]$.

The dialogical development is straightforward if we recall from I.2.2 that the application of a function follows the following rule

\begin{tabular}{|l|l|l|}
\hline Posit & Challenge & Defence \\
\hline $\mathbf{X} ! \mathrm{p}: \varphi\left[\mathrm{f}\left(\mathrm{k}_{1}\right)\right]$ & $\mathbf{Y ~ f}\left(\mathrm{k}_{1}\right) / ?$ & $\begin{array}{l}\mathbf{X ~ p ~}: \varphi\left[\mathrm{k}_{2} / \mathrm{f}\left(\mathrm{k}_{1}\right]\right. \\
\left.<\varphi\left[\mathrm{f}\left(\mathrm{k}_{1}\right)\right]=\varphi\left[\mathrm{k}_{2 /} \mathrm{f}\left(\mathrm{k}_{1}\right)\right]: \text { set }\right]>\end{array}$ \\
\hline
\end{tabular}

Notice how close this formulation is to the one proposed by Sandu/Jacot (2012): the crucial difference is that in Sundholm's formulation the relevant functions are explicit proof-objects.

\footnotetext{
${ }^{57}$ Sundholm uses the membership sign instead of the colon. For a discussion on this aspect of the notation in CTT, see Granström (2011).
} 


\section{III.3 Final remarks}

As already mentioned, Hintikka's remark on binding scope touches a crucial point in the semantics of anaphora namely, that of structure of dependences, which naturally leads to game-theoretical interpretation. However, on our view, this point involves the dependences between play-objects in general and choices for the substitution of the instructions in particular. A framework such as the one of CTT was necessary to make the point of these dependences explicit.

The dialogical approach implements these dependences within a game-theoretical analysis. Indeed without such an approach choice dependences cannot be expressed at the object language level of first-order logic. As already mentioned the point can be put in the following way: if binding scope amounts to dependences, dependences are understood as interactions, specific forms of the latter represent winning-strategies and we would like to express this in the object language, then it looks natural to embed such structures in a frame where proof-objects are expressed at the object language level as truth-makers of first-order expressions. Moreover, if we go a step deeper in the analysis, it looks natural to introduce a more fundamental semantic level on the basis of which strategies are constructed: this is precisely what the dialogical approach provides by furnishing both playobjects and strategic-objects (the latter are those play-objects relevant for a winning strategy).

More generally, the steps of substitution and identity involving commitments and entitlements so central to Brandom's reading of anaphora cannot be made explicit without such a frame either. Notice that Brandom's (1994, p. 493) analysis of, for example, the donkey sentence, leaves play-object dependences implicit. More precisely, because Brandom does not use an explicit inferential frame as the one of CTT, he does not distinguish the types set, such as man and donkey over which the subset of all those men who own a men is defined (recall that, according to the CTT-reading, all those men who own a don$k e y$ is an existential defined over the sets man and donkey).

One other advantage of the dialogical approach is that the meaning of the anaphoric expression is obtained at the play-level and not through the existence of winning strategy for a player as in GTS. That is an advantage because it shows how we can understand the meaning of anaphoric pronoun without knowing how to win the game: it is enough that one understands all the steps the Proponent is committed to in a dialogical game. This is linked to our discussion in the introduction on how the distinction between the play and the strategy seems to provide a way to give shape to Brandom's (1994, p. 636) claim that the "grasp of concepts" amounts to the mastery of inferential roles but this only requires enough knowledge of the moves in the relevant games. The dialogician responds: enough means to know the relevant moves that have to be brought forward (according to the local rules) during a play.

\section{Prospectives}

The development of a dialogical approach to CTT is still at its beginnings and many open issues have yet to be tackled. Let us briefly mention only two main research paths that are works in progress: 
1. The Meaning of Conversations: In his book The Interactive Stance, J. Ginzburg (2012) stresses the utmost importance of taking conversational (interactive) aspects into account in order to develop a theory of meaning, where meaning is constituted during the interaction. In order to implement such a theory of meaning Ginzburg makes use of Constructive Type Theory where the so-called "metalogical" rules that constitute meaning are explicitly imported into the object language. Moreover, Ginzburg designs some kind of language games called dialogicalgameboards in order to capture the dynamic aspects of every-day dialogues. Now, if we take seriously the claim that meaning is constituted by and within interaction then we expect that the semantics of the underlying logical elements is also understood dialogically. In this context, a dialogical approach to Constructive Type Theory provides both a dialogical frame for the underlying logic and a natural link to the dialogical-gameboards. Rahman (2014) has started tackling this issue but a full development is still to be worked out.

2. Modal Epistemic Logic and Belief Revision: In the context of CTT, the variable in a hypothetical such as $p(x): P(x: S)$ represents an unknown element of $S$ that can be instantiated by some $s$ when the required knowledge is available. ${ }^{58}$ Thus, in this framework, instantiating the unknown element $x$ by some $s$ known to be a fixed (but arbitrary) element of $S$ describes the passage from belief to knowledge. Using the current terminology of epistemic logic as an analogy - in the style of Hintikka (1962) - we say that a judgement of the form $x: S$ expresses belief rather than knowledge. In fact, for this transition to count as a transition to knowledge, it is not only necessary that $s: S$, but it is also necessary that the proof-object $s$ is of the adequate sort. ${ }^{59}$ In other words, we also need to have the definition $x=s: S$. This definition of $x$ can be called an anchoring of the hypothesis (belief) $S$ in the actual world. ${ }^{60}$ Thus, the result of this anchoring process yields $p(x=s): P(s: S)$. In fact after some seminal work of Aarne Ranta (1991) there are ongoing developments by Giuseppe Primiero $(2008,2012)$ on applying CTT to belief revision. However neither dynamic aspects provided by game-theoretical approaches has not been considered - where knowledge acquisition is depicted as resulting from interaction - nor the modal formalizations of belief revision have been yet studied in this framework. B. Dango has started to work out the ways to combine the CTT formulation of modal logic with the dialogical approach.

\footnotetext{
${ }^{58}$ Cf. Granström (2011, pp. 110-112). In fact, chapter V of Granström (2011) contains a thorough discussion of the issue.

${ }^{59}$ Cf. Ranta (1994, pp. 151-154).

${ }^{60}$ Cf. Ranta (1994, p. 152).
} 


\section{Appendix: Standard dialogical games}

Let $\mathrm{L}$ be a first-order language built as usual upon the propositional connectives, the quantifiers, a denumerable set of individual variables, a denumerable set of individual constants and a denumerable set of predicate symbols (each with a fixed arity).

We extend the language $L$ with two labels $\boldsymbol{O}$ and $\boldsymbol{P}$, standing for the players of the game, and the two symbols '!' and '?'. When the identity of the player does not matter, we use variables $\boldsymbol{X}$ or $\boldsymbol{Y}$ (with $\boldsymbol{X} \neq \boldsymbol{Y}$ ). A move is an expression of the form ' $\boldsymbol{X}-e^{\prime}$, where $e$ is either of the form '! $\varphi$ ' for some sentence $\varphi$ of $L$ or of the form '?[! $\left.\varphi_{1}, \ldots, ! \varphi_{n}\right]$ '.

The particle (or local) rules for standard dialogical games are given in the following table:

\begin{tabular}{|c|c|c|c|c|}
\hline Previous move & $\mathbf{X} ! \varphi \wedge \psi$ & $\mathbf{X} ! \varphi \vee \psi$ & $\mathbf{X} ! \varphi \rightarrow \psi$ & $\mathbf{X} ! \neg \varphi$ \\
\hline Challenge & $\begin{array}{c}\mathbf{Y} ?[! \varphi] \text { or } \\
\mathbf{Y} ?[! \psi]\end{array}$ & $\mathbf{Y} ?[! \varphi, ! \psi]$ & $\mathbf{Y} ! \varphi$ & $\mathbf{Y} ! \varphi$ \\
\hline Defence & $\begin{array}{c}\mathbf{X} ! \varphi \\
\text { resp. } \mathbf{X} ! \psi\end{array}$ & $\begin{array}{c}\mathbf{X} ! \varphi \\
\text { or } \mathbf{X} ! \psi\end{array}$ & $\mathbf{X} ! \psi$ & -- \\
\hline
\end{tabular}

\begin{tabular}{|c|c|c|}
\hline Previous move & $\mathbf{X} ! \forall x \varphi$ & $\mathbf{X} ! \exists x \varphi$ \\
\hline Challenge & $\mathbf{Y} ?\left[! \varphi\left(x / a_{i}\right)\right]$ & $\mathbf{Y}-\left[! \varphi\left(x / a_{1}\right), \ldots, ! \varphi\left(x / a_{n}\right)\right]$ \\
\hline Defence & $\mathbf{X} ! \varphi\left(x / a_{i}\right)$ & $\begin{array}{c}\mathbf{X} ! \varphi\left(x / a_{i}\right) \\
\text { with } 1 \leq \mathrm{i} \leq \mathrm{n}\end{array}$ \\
\hline
\end{tabular}

In this table, the $a_{i}$ s are individual constants and $\varphi\left(x / a_{i}\right)$ denotes the formula obtained by replacing every free occurrence of $x$ in $\varphi$ by $a_{i}$. When a move consists in a question of the form '?[! $\left.\varphi_{1}, \ldots, ! \varphi_{n}\right]$ ', the other player chooses one formula among $\varphi_{1}, \ldots$, $\varphi_{n}$ and plays it. We thus distinguish conjunction from disjunction and universal quantification from existential quantification in terms of which player chooses. With conjunction and universal quantification, the challenger chooses which formula he asks for. With disjunction and existential quantification, it is the defender who can choose between various formulas. Notice that there is no defence in the particle rule for negation.

Particle rules provide an abstract description of how the game can proceed locally: they specify the way a formula can be challenged and defended according to its main logical constant. In this way the particle rules govern the local level of meaning. Strictly speaking, the expressions occurring in the table above are not actual moves because they feature formula schemata and the players are not specified. Moreover, these rules are indifferent to any particular situations that might occur during the game. For these reasons we say that the description provided by the particle rules is abstract.

Since the players' identities are not specified in these rules, particle rules are symmetric: the rules are the same for the two players. The local meaning being 
symmetric (in this sense) is one of the greatest strengths of the dialogical approach to meaning. It is in particular the reason why the dialogical approach is immune to a wide range of trivializing connectives such as Prior's tonk. ${ }^{61}$

The expressions occurring in particle rules are all move schematas. The words "challenge" and "defence" are convenient to name certain moves according to their relation with other moves which can be defined in the following way. Let $\sigma$ be a sequence of moves. The function $\mathrm{p}_{\sigma}$ assigns a position to each move in $\sigma$, starting with 0 . The function $\mathrm{F}_{\sigma}$ assigns a pair $[m, Z]$ to certain moves $\mathrm{N}$ in $\sigma$, where $m$ denotes a position smaller than $\mathrm{p}_{\sigma}(\mathrm{N})$ and $Z$ is either $C$ or $D$, standing respectively for "challenge" and "defence". That is, the function $\mathrm{F}_{\sigma}$ keeps track of the relations of challenge and defence as they are given by the particle rules. Consider for example the following sequence $\sigma$ :

\section{$P ! \varphi \wedge \psi, P ! \chi \wedge \psi, O ?[! \varphi], P ! \varphi$}

In this sequence we have for example $\mathrm{p}_{\sigma}(\boldsymbol{P} ! X \wedge \psi)=1$.

A play is a legal sequence of moves, i.e., a sequence of moves which observes the game rules. Particle rules are not the only rules which must be observed in this respect. In fact, it can be said that the second kind of rules named structural rules are the ones giving the precise conditions under which a given sequence is a play. The dialogical game for $\varphi$, written $\mathscr{D}(\varphi)$, is the set of all plays with $\varphi$ being the thesis (see the Starting rule below). The structural rules are the following:

SR0 (Starting rule). Let $\varphi$ be a complex sentence of $L$ and $i, j$ be positive integers. For every $\zeta \in \mathscr{D}(\varphi)$ we have:

$-\mathrm{p}_{3}(\boldsymbol{P} ! \varphi)=0$,

$-\mathrm{p}_{3}(\boldsymbol{O} \mathrm{n}:=i)=1$,

$-\mathrm{p}_{r}(\boldsymbol{P} \mathrm{m}:=j)=2$.

In other words, any play $\zeta$ in $\mathscr{D}(\varphi)$ starts with $\boldsymbol{P}$ positing $\varphi$. We call $\varphi$ the thesis of both the play and the dialogical game. After that, the Opponent and the Proponent successively choose a positive integer called repetition rank. The role of these integers is to ensure that every play ends after finitely many moves in the way specified by the next structural rule.

\section{SR1 (Classical game-playing rule).}

- Let $\zeta \in \mathscr{D}(\varphi)$. For every Min $\zeta$ with $\mathrm{p}_{\zeta}(\mathrm{M})>2$ we have $\mathrm{F}_{\zeta}(\mathrm{M})=\left[m^{\prime}, Z\right]$ with $m^{\prime}<\mathrm{p}_{\zeta}(\mathrm{M})$ and $Z \in\{C, D\}$.

- Let $\mathrm{r}$ be the repetition rank of player $\boldsymbol{X}$ and $\zeta \in \mathscr{D}(\varphi)$ such that

- the last member of $\zeta$ is a $\boldsymbol{Y}$-move,

- $\mathrm{M}_{0}$ is a $\boldsymbol{Y}$-move of position $m_{0}$ in $\zeta$,

- M1,..,Mn are $\boldsymbol{X}$-moves in $\zeta$ such that $\mathrm{F}_{\zeta}\left(\mathrm{M}_{1}\right)=\ldots \mathrm{F}_{\zeta}\left(\mathrm{M}_{\mathrm{n}}\right)=\left[m_{0}, Z\right]$.

Consider the sequence ${ }^{62} \zeta^{\prime}=\zeta^{*} N$ where $N$ is an $\boldsymbol{X}$-move such that $F_{\zeta^{\prime}}(N)=\left[m_{0}, Z\right]$. We have $\zeta^{\prime} \in \mathscr{D}(\varphi)$ only if $\mathrm{n}<\mathrm{r}$.

\footnotetext{
${ }^{61}$ See Rahman et al.(2009) and Rahman(2012).
} 
The first part of the rule states that every move after the repetition rank choices is either a challenge or a defence. The second part ensures finiteness of plays by setting the player's repetition rank as the maximum number of times he can challenge or defend against a given move by the other player.

\section{SR2 (Formal rule).}

Let $\psi$ be an elementary sentence, $\mathrm{N}$ be the move $\boldsymbol{P} ! \psi$ and $\mathrm{M}$ be the move $\boldsymbol{O} ! \boldsymbol{\text { }}$. A sequence $\zeta$ of moves is a play only if we have: if $N \in \zeta$ then $M \in \zeta$ and $p_{\zeta}(M)<p_{\zeta}(N)$.

That is, the Proponent can play an elementary sentence only if the Opponent has played it previously. The Formal rule is one of the characteristic features of the dialogical approach: other game-based approaches do not have it.

Helge Rückert pointed out that the formal rule triggers a novel notion of validity: Geltung (Legitimacy). ${ }^{63}$ Indeed with this rule the dialogical framework comes with an internal account for elementary sentences: an account in terms of interaction only, without depending on metalogical meaning explanations for the non-logical vocabulary. More prominently this means that the dialogical account does not rely - contrary to Hintikka's GTS games - on the model-theoretical approach to meaning for atomic formulas.

From there Rückert claims, and on this point we disagree with him, that Geltung is the idea that interaction emerges without knowing (or without needing to know) what the meaning of elementary sentences are. We disagree because the question of the meaning of elementary sentences (and more generally, of non-logical vocabulary) cannot be disregarded if the dialogical framework is meant to provide a general theory of meaning. In our view, thus, Rückert's interpretation of Geltung dissolves the meaning of elementary sentences into the formal rule. This is mainly due to the fact that the standard version of the framework does not have the means to express a semantic at the objectlanguage level in terms of asking and giving reasons for elementary sentences. As a consequence, the standard formulation simply relies on the formal rule which amounts to entitle $\boldsymbol{P}$ to copy-cat the elementary sentences brought forward by $\boldsymbol{O}$. According to us, the introduction of play-objects provides a solution to this without giving up on the internal aspect linked with Geltung. We will develop this idea when we give the particle rules in section I.3 and after we introduce a "modified formal rule" in section I.4.

Here is some terminology for the last structural rule in standard dialogical games. A play is called terminal when it cannot be extended by further moves in compliance with the rules. We say it is $\boldsymbol{X}$-terminal when the last move in the play is an $\boldsymbol{X}$-move.

SR3 (Winning rule). Player $\boldsymbol{X}$ wins the play $\zeta$ only if it is $\boldsymbol{X}$-terminal.

Consider for example the following sequences of moves:

$$
\begin{aligned}
& \mathbf{P}-\mathrm{Q} a \wedge \mathrm{Qb}, \mathbf{O}-\mathrm{n}:=1, \mathbf{P}-\mathrm{m}:=6, \mathbf{O}-?[\mathrm{Qa}], \mathbf{P}-\mathrm{Qa} \\
& \mathbf{P}-\mathrm{Qa} \rightarrow \mathrm{Qa}, \mathbf{O}-\mathrm{n}:=1, \mathbf{P}-\mathrm{m}:=12, \mathbf{O}-\mathrm{Q} \text {, P-Qa }
\end{aligned}
$$

\footnotetext{
${ }^{62}$ We use $\zeta^{\star} \mathrm{N}$ to denote the sequence obtained by adding move $\mathrm{N}$ to the play $\zeta$.

${ }^{63}$ Ruckert (2011b).
} 
The first one is not a play because it breaks the Formal rule: with his last move, the Proponent plays an elementary sentence which the Opponent has not played beforehand. By contrast, the second sequence is a play in $\mathscr{D}(\mathbf{P}-\mathrm{Qa} \rightarrow \mathrm{Qa})$. We often use a convenient table notation for plays. For example, we can write this play as follows:

\begin{tabular}{|c|c|c|c|c|}
\hline & O & & $\mathbf{P}$ & \\
\hline & & & $! \mathrm{Qa} \rightarrow \mathrm{Qa}$ & 0 \\
\hline 1 & $\mathrm{n}:=1$ & & $\mathrm{~m}:=12$ & 2 \\
\hline 3 & !Qa & (0) & !Qa & 4 \\
\hline
\end{tabular}

The numbers in the external columns are the positions of the moves in the play. When a move is a challenge, the position of the challenged move is indicated in the internal columns, as with move 3 in this example. Notice that such tables carry the information given by the functions $\mathrm{p}$ and $\mathrm{F}$ in addition to represent the play itself.

However, when we want to consider several plays together - for example when building a strategy - such tables are not that perspicuous. So we do not use them to deal with dialogical games for which we prefer another perspective. The extensive form of the dialogical game $\mathscr{D}(\varphi)$ is simply the tree representation of it, also often called the gametree. More precisely, the extensive form $\mathrm{E}_{\varphi}$ of $\mathscr{D}(\varphi)$ is the tree $(\mathrm{T}, \ell, \mathrm{S})$ such that:

i) Every node $\mathrm{t}$ in $\mathrm{T}$ is labelled with a move occurring in $\mathscr{D}(\varphi)$

ii) $\ell: T \rightarrow \mathbf{N}$

iii) $\mathrm{S} \subseteq \mathrm{T}^{2}$ with:

- There is a unique $t_{0}$ (the root) in $T$ such that $\ell\left(t_{0}\right)=0$, and $t_{0}$ is labelled with the thesis of the game,

- For every $t \neq t_{0}$ there is a unique $t^{\prime}$ such that $t$ 'St,

- For every $\mathrm{t}$ and $\mathrm{t}^{\prime}$ in $\mathrm{T}$, if $\mathrm{tSt} \mathrm{t}^{\prime}$ then $\ell\left(\mathrm{t}^{\prime}\right)=\ell(\mathrm{t})+1$,

- Let $\zeta \in \mathscr{D}(\varphi)$ such that $\mathrm{p}_{\zeta}\left(\mathrm{M}^{\prime}\right)=\mathrm{p}_{\zeta}(\mathrm{M})+1$. If $\mathrm{t}$ and $\mathrm{t}^{\prime}$ are respectively labelled with $\mathrm{M}$ and $\mathrm{M}^{\prime}$, then $\mathrm{tSt}^{\prime}$.

Many dialogical game metalogical results are obtained by leaving the level of rules and plays to move to the level of strategies. Significant among these results are the ones concerning the existence of winning strategies for a player. We will now define these notions and give examples of such results.

A strategy for player $\boldsymbol{X}$ in $\mathscr{D}(\varphi)$ is a function which assigns an $\boldsymbol{X}$-move M to every non terminal play $\zeta$ having a $\boldsymbol{Y}$-move as last member such that extending $\zeta$ with $\mathrm{M}$ results in a play. An $\boldsymbol{X}$-strategy is winning if playing according to it leads to $\boldsymbol{X}$ 's victory no matter how $\boldsymbol{Y}$ plays.

Strategies can be considered from the perspective of extensive forms: the extensive form of an $\boldsymbol{X}$-strategy s in $\mathscr{D}(\varphi)$ is the tree-fragment $\mathrm{S}_{\varphi}=\left(\mathrm{T}_{\mathrm{s}}, \mathrm{l}_{\mathrm{S}}, \mathrm{S}_{\mathrm{s}}\right)$ of $\mathrm{E}_{\varphi}$ such 
that:

i) The root of $S_{\varphi}$ is the root of $E_{\varphi}$,

ii) Given a node $t$ in $\mathrm{E}_{\varphi}$ labelled with an $\boldsymbol{X}$-move, we have $\mathrm{t}^{\prime} \in \mathrm{T}_{\mathrm{s}}$ and $\mathrm{tS}_{\mathrm{s}} \mathrm{t}^{\prime}$ whenever $\mathrm{tSt}$ '.

iii) Given a node $\mathrm{t}$ in $\mathrm{E}_{\varphi}$ labelled with a $\boldsymbol{Y}$-move and with at least one $\mathrm{t}^{\prime}$ such that $\mathrm{tSt}$ ', we have a unique $\mathrm{s}(\mathrm{t})$ in $\mathrm{T}_{\mathrm{s}}$ with $\mathrm{t} \mathrm{S}_{\mathrm{s}} \mathrm{s}(\mathrm{t})$ and $\mathrm{s}(\mathrm{t})$ is labelled with the $\boldsymbol{X}$-move prescribed by s.

Here are some results pertaining to the level of strategies: ${ }^{64}$

- Winning $\boldsymbol{P}$-strategies and leaves. Let w be a winning $\boldsymbol{P}$-strategy in $\mathscr{D}(\varphi)$. Then every leaf in the extensive form $\mathrm{W}_{\varphi}$ of $\mathrm{W}$ is labelled with a $\boldsymbol{P}$ elementary sentence.

- Determinacy. There is a winning $\boldsymbol{X}$-strategy in $\mathscr{D}(\varphi)$ if and only if there is no winning $\mathbf{Y}$ strategy in $\mathscr{D}(\varphi)$.

- Soundness and Completeness of Tableaux. Consider first-order tableaux and first-order dialogical games. There is a tableau proof for $\varphi$ if and only if there is a winning $\boldsymbol{P}$ strategy in $\mathscr{D}(\varphi)$.

The fact that existence of a winning $\boldsymbol{P}$-strategy coincides with validity (there is a winning $\boldsymbol{P}$-strategy in $\mathscr{D}(\varphi)$ if and only if $\varphi$ is valid) follows from the soundness and completeness of the tableau method with respect to model-theoretical semantics.

Regarding several results, extensive forms of strategies have key parts: one of the parts of a winning strategy, called the core of the strategy, is actually that on which one works when considering translation algorithms such as the procedures. The basic idea behind the notion of core is to get rid of redundant information (for example, different orders of moves) which we find in extensive forms of strategies (see Clerbout and Rahman (2015).

\footnotetext{
${ }^{64}$ These results are proven, together with others, in Clerbout (2014a).
} 


\section{Literature}

S. Abramsky and P.A. Mellies (1999). "Concurrent Games and Full Completeness". Proceedings of the 14th International Symposium on Logic in Computer Science, Trento: IEEE Computer Society Press, pp. $431-442$.

J. L. Austin (1946). "Other Minds". Proceedings of the Aristotelian Society, Supplementary Volume 20, pp. $148-187$.

J. Bell (2009). The Axiom of Choice. London: College Publications.

A. Blass (1992). "A game semantics for linear logic". Annals of Pure and Applied Logic, 56, pp.183-220.

R. Brandom (1994). Making it Explicit. Cambridge-Mass/London: Harvard UP.

R. Brandom (2000). Articulating Reasons. Cambridge-Mass/London: Harvard UP.

N. Clerbout (2014a). "First-order dialogical games and tableaux". Journal of Philosophical Logic, 43(4), pp. 785-801. doi: 10.1007/s10992-013-9289-z. URL http://dx.doi.org/10.1007/s10992-013-9289-z,

N. Clerbout (2014b). La sémantique dialogique: Concepts fondamentaux et éléments de metathéorie. London: College Publications.

N. Clerbout (2014c). "Finiteness of Plays and the Dialogical Problem of Decidability". IfCoLog Journal of Logics and their Applications, 1(1), pp. 115-130.

N. Clerbout, M.H. Gorisse, and S. Rahman (2011). "Context-sensitivity in Jain philosophy: A dialogical study of Siddharsiganis Commentary on the Handbook of Logic". Journal of Philosophical Logic, 40(5), pp. 633-662.

N. Clerbout and S. Rahman (2013). "On Dialogues, Predication and Elementary Sentences". Revista de Humanidades de Valparaíso, 2, pp. 7-46..

N. Clerbout and S. Rahman (2015). Linking Game-Theoretical Approaches with Constructive Type Theory: Dialogical Strategies, CTT Demonstrations and the Axiom of Choice. Dordrecht: Springer - in print.

H. Enderton (1970). "Finite partially ordered quantifiers". Zeitschrift für mathematische Logik, 16, pp. 393-397.

S. Feferman (2006). "What kind of logic is "Independence Friendly" logic?". In Randall E. Auxier and Lewis Edwin Hahn (eds.), The Philosophy of Jaakko Hintikka, Chicago: Open Court - Library of Living Philosophers, vol. 30, pp. 453-469.

W. Felscher (1985). "Dialogues as a foundation for intuitionistic logic". In D. Gabbay and F. Guenthner (eds.), Handbook of Philosophical Logic, Dordrecht: Kluwer, vol. 3, pp. 341-372.

W. Felscher (1994). "Review of Jean E. Rubin 'Mathematical logic: applications and theory"'. The Journal of Symbolic Logic, 59, pp. 670-671.

V. Fiutek, H. Rückert, and S. Rahman (2010). "A dialogical semantics for Bonannos system of belief revision”. In P. Bour and alii (eds.), Constructions, London: College Publications, pp. 315-334.

M. Fontaine (2013). Argumentation et engagement ontologique. Être, c'est être choisi. London: College Publications. 
J. Ginzburg (2012). The Interactive Stance: Meaning for Conversation. Oxford: Oxford University Press.

J. Y. Girard (1999). "On the meaning of logical rules I : syntax vs. semantics". In U. Berger and H. Schwichtenberg (eds.), Computational Logic, Heidelberg: Springer, pp. 215-272.

J. Granström (2011). Treatise on Intuitionistic Type Theory. Dordrecht: Springer.

J. Hintikka (1962). Knowledge and Belief. Ithaca: Cornell University Press.

J. Hintikka (1973). Logic, Language-Games and Information: Kantian Themes in the Philosophy of Logic. Oxford: Clarendon Press.

J. Hintikka (1996a). The Principles of Mathematics Revisited. Cambridge: Cambridge University Press.

J. Hintikka (1996b). Lingua Universalis vs. Calculus Ratiocinator: An Ultimate Presupposition of Twentieth-Century Philosophy, Dordrecht: Kluwer.

J. Hintikka (1997). Defining Truth, the Whole Truth and Nothing but the Truth. Helsinki: University of Helsinki - Reports from the Department of Philosophy, no. 2.

J. Hintikka (1999). Inquiry as Inquiry: A Logic of Scientific Discovery. Dordrecht: Springer.

J. Hintikka and J. Kulas (1985). Anaphora and Definite Descriptions, Two Applications of Game- Theoretical Semantics. Dordrecht/Boston/Lancaster: D. Reidel.

J. Hintikka and G. Sandu (1989). "Informational Independence as a Semantical Phenomenon". In J. E. Fenstad, I. T. Frolov, and R. Hilpinen (eds.), Logic, Methodology and Philosophy of Science, Amsterdam: Elsevier, vol.8, pp. 571-589.

J. Hintikka and G. Sandu (1997). "Game-theoretical semantics". In J. van Benthem and A. ter Meulen, (eds.), Handbook of Logic and Language, Amsterdam: Elsevier, pp. 361-410.

J. Hintikka, I. Halonen and A. Mutanen (1999). "Interrogative Logic as a General Theory of Reasoning". In Hintikka (1999), pp. 47-90.

W. Hodges (2001). "Dialogue foundations. a sceptical look". Proceedings of the Aristotelian Society, supplementary volume LXXV, pp. 17-32.

W. Hodges (2004, revised 2013). "Logic and Games". In Edward N. Zalta (ed.), The Stanford Encyclopedia of Philosophy, URL $=<$ http://plato.stanford.edu/archives/spr2013/entries/logic-games/>.

R. Jovanovic. (2013). "Hintikka's Take on the Axiom of Choice and the Constructivist Challenge". Revista de Humanidades de Valparaíso, $\mathrm{N}^{\circ}$ 2, 135-152.

W. Kamlah and P. Lorenzen (1972). Logische Propädeutik: Stuttgart/Weimar: Metzler, $2^{\text {nd }}$ edition.

W. Kamlah and P. Lorenzen (1984). Logical Propaedeutic, Lanham Md.: University Press of America, English translation of Kamlah/Lorenzen (1972) by H. Robinson.

L. Keiff (2007). Le Pluralisme Dialogique: Approches dynamiques de l'argumentation formelle. Lille: $\mathrm{PhD}$ - thesis - Lille 3.

L. Keiff (2009). "Dialogical Logic". In Edward N. Zalta (ed.), The Stanford Encyclopedia of Philosophy, URL http://plato.stanford.edu/entries/logic-dialogical/. 
A. Lecomte and M. Quatrini (2010) "Pour une étude du langage via l'interaction: Dialogues et sémantique en Ludique". Mathématiques et Sciences Humaines, 189, pp. 37-67.

A. Lecomte (2011). Meaning, Logic and Ludics. London: Imperial College Press.

A. Lecomte and M. Quatrini (2011). "Figures of dialogue: A view from Ludics". Synthese, 183(1), pp. 5985.

A. Lecomte and S. Tronçon, editors (2011). Ludics, Dialogues and Interaction: PRELUDE Project 20062009. Revised Selected Papers. Berlin/Heidelberg: Springer.

K. Lorenz (1970). Elemente der Sprachkritik.Eine Alternative zum Dogmatismus und Skeptizismus in der Analytischen Philosophie. Frankfurt: Suhrkamp.

K. Lorenz (2001). "Basic objectives of dialogue logic in historical perspective". In S. Rahman and H. Rückert (eds.), New Perspectives in Dialogical Logic, special volume Synthese 127 (1-2), pp. 255-263.

K. Lorenz (2010a). Logic, Language and Method: On Polarities in Human Experience. Berlin/New York: De Gruyter.

K. Lorenz (2010b). Philosophische Variationen: Gesammelte Aufstze unter Einschluss gemeinsam mit J"urgen Mittelstraß geschriebener Arbeiten zu Platon und Leibniz. Berlin and New York: De Gruyter.

P. Lorenzen (1995). Einführung in die operative Logik und Mathematik, Berlin: Springer.

P. Lorenzen and K. Lorenz (1978). Dialogische Logik. Darmstadt: Wissenschaftliche Buchgesellschaft.

P. Lorenzen and O. Schwemmer (1975). Konstruktive Logik, Ethik und Wissenschaftstheorie. Mannheim: Bibliographisches Institut, second edition.

S. Magnier (2013). Approche dialogique de la dynamique épistémique et de la condition juridique. London: College Publications.

M. Marion (2006). "Hintikka on Wittgenstein: From Language-Games to Game Semantics". In T. Aho and A.-V. Pietarinen (eds.), Truth and Games, Essays in Honour of Gabriel Sandu, Acta Philosophica Fennica, vol. 78, pp. 223-242.

M. Marion (2009). "Why Play Logical Games ?”. In O. Majer, A.-V. Pietarinen and T. Tulenheimo (eds.), Logic and Games, Foundational Perspectives, Dordrecht: Springer, pp. 3-26.

M. Marion (2010). "Between Saying and Doing : From Lorenzen to Brandom and Back". In P. E. Bour, M. Rebuschi and L. Rollet (eds.), Constructions, London: College Publications, pp. 489-497.

P. Martin-Löf (1984). Intuitionistic Type Theory. Notes by Giovanni Sambin of a series of lectures given in Padua, June 1980. Naples: Bibliopolis.

P. Martin-Löf (2006). "100 years of Zermelo's Axiom of Choice: what was the problem with it?". The Computer Journal, 49(3), pp. 345-350.

C. Penco (2005). "Keeping track of indiviudals. Brandom's analysis of Kripke's puzzle and the content of belief". Pragmatics and Cognition, 13 (1), pp. 177-201.

A. Popek (2012). "Logical dialogues from Middle Ages". In C. Barés Gómez, S. Magnier and F. J. Salguero (eds.), Logic of Knowledge. Theory and Applications, London: College Publications, pp. 223-244. 
D. Prawitz (1979). "Proofs and the meaning and completeness of the logical constants". In J. Hintikka, I. Niiniluoto and E.Saarinen (eds.), Essays on Mathematical and Philosophical Logic, Dordrecht: Reidel, pp. 25-40.

D. Prawitz (2012). "Truth and Proof in Intuitionism". In P. Dybjer, S. Lindström, E. Palmgren and G. Sundholm (eds.), Epistemology versus Ontology: Essays on the Philosophy and Foundations of Mathematics in Honour of Per Martin-Löf, Dordrecht: Springer, pp. 45-68.

G. Primiero (2008). "Constructive modalities for information", Talk given at the Young Researchers Days in Logic, Philosophy and History of Science, Brussels, 1-2 September 2008.

G. Primiero (2012). "A contextual type theory with judgemental modalities for reasoning from open assumptions”. Logique et Analyse, 220, pp. 579-600.

S. Rahman (1993). Über Dialogue, Protologische Kategorien und andere Seltenheiten. Frankfurt/Paris/N. York: P. Lang.

S. Rahman (2012). "Negation in the Logic of first degree entailment and tonk: A dialogical study". In S. Rahman, G. Primiero, and M. Marion (eds.), The Realism-Antirealism Debate in the Age of Alternative Logics, Dordrecht: Springer, pp. 213-250.

S. Rahman (2014). "From Dialogue To Dialogue: Conversations and the Dialogical Approach to Meaning". In C. Bowao et S. Rahman. De l'orature à l'écriture, London-King's College: College Publications, pp. 70-106.

S. Rahman (2015) “On Hypothetical Judgements and Leibniz's Notion of Conditional Right". In A. Armgardt, P. Canivez, and S. Chassagnard-Pinet (eds.), Legal reasoning and Logic. Past \& Present interactions. Dordrecht: Springer, pp. 109-167.

S. Rahman and N. Clerbout (2013). "Constructive Type Theory and the Dialogical Approach to Meaning". The Baltic International Yearbook of Cognition, Logic and Communication:Games, Game Theory and Game Semantics, 8, pp. 1-72. Also online in: www.thebalticyearbook.org.

S. Rahman and N. Clerbout (2015). "Constructive Type Theory and the Dialogical Turn - A new Start for Erlangen Constructivism". In J. Mittelstrass and C. von Bülow (ed.), Dialogische Logik, Münster: Mentis, pp. $127-184$.

S. Rahman and L. Keiff (2005). "On how to be a dialogician". In D. Vanderveken (ed.), Logic, Thought, and Action, Dordrecht: Kluwer, pp. 359-408.

S. Rahman and L. Keiff (2010). "La Dialectique entre logique et rhetorique". Revue de Métaphysique et de Morale, 66(2), pp. 149-178.

S. Rahman and J. Redmond (2015a). "Armonía Dialógica: tonk Teoría Constructive de Tipos y Reglas para Jugadores Anónimos", Constructive Type Theory and Player-Independent Rules". Theoria, 2015, in print.

S. Rahman and J. Redmond (2015b). "A Dialogical Frame for Fictions as Hypothetical Objects". UNISINOS, to appear.

S. Rahman and T. Tulenheimo (2009). "From Games to Dialogues and Back: Towards a General Frame for Validity". In O. Majer. A. Pietarinen and T. Tulenheimo (eds.), Games: Unifying Logic, Language and Philosophy, Dordrecht: Springer, pp. 153-208.

S. Rahman, N. Clerbout, and L. Keiff (2009). "On Dialogues and Natural Deduction”. In S. Rahman and G. Primiero (eds), Acts of Knowledge: History, Philosophy and Logic, London: College Publications, pp. 301336. 
S. Rahman, N. Clerbout, and Z. McConaughey (2014). "On play-objects in dialogical games. Towards a Dialogical approach to Constructive Type Theory". In P. Allo/V. v. Kerkhove (ed.), Modestly radical or radically modes. Festschrift for Jean-Paul van Bendegem, London: College Publications, pp. 127-154.

A. Ranta (1988). "Propositions as games as types". Synthese, 76, pp. 377-395.

A. Ranta (1991). “Constructing possible worlds”. Theoria, 57(1-2), pp. 77-99.

A. Ranta (1994). Type-Theoretical Grammar. Oxford: Clarendon Press.

S. Read (2008). "Harmony and modality". In: C. Dégremont. L. Keiff. H. Rückert (eds.), Dialogues, Logics and Other Strange Things: Essays in Honour of Shahid Rahman, London: College Publications, pp. 285303.

S. Read (2010). "General Elimination Harmony and the Meaning of the Logical Constants". Journal of Philosophical Logic, 39 (5), pp. 557-576.

J. Redmond (2010). Logique dynamique de la fiction: Pour une approche dialogique. London: College Publications.

J. Redmond and M. Fontaine (2011). How to Play Dialogues: An Introduction to Dialogical Logic. London: College Publications.

H. Rückert (2011a). Dialogues as a Dynamic Framework for Logic. London: College Publications.

H. Rückert (2011b). "The Conception of Validity in Dialogical Logic".Talk at the workshop Proofs and Dialogues, Tübingen.

G. Sandu (1991). Studies in Game-Theoretical Logics and Semantics. Ph.D. thesis, Helsinki: University of Helsinki.

G. Sandu (1997). "On the theory of anaphora: dynamic predicate logic vs. game-theoretical semantics". Linguistics and Philosophy, 20, pp.147-174.

G. Sandu, J. Jacot (2012). "Quantification and Anaphora in Natural Language”. In R. Schantz (ed), Prospect for meaning, Walter de Gruyter Inc, Berlin/New York, pp. 609-628.

P. Schröder-Heister (2008). "Lorenzen's operative justification of intuitionistic logic". In M. Bourdeau, M. van Atten and P. Boldini (eds.), One Hundred Years of Intuitionism (1907-2007), Basel: Birkhäuser, pp. 214-240.

J. M. Sterling (2015). "Note on Diaconescu's theorem". Online in http://www.jonmsterling.com/posts/2015-04-24-note-on-diaconescus-theorem.html

G. Sundholm (1986). "Proof-theory and meaning". In D. Gabbay and F. Guenthner (eds.), Handbook of Philosophical Logic, volume 3, Dordrecht: Reidel, , pp. 471-506.

G. Sundholm (1997) "Implicit epistemic aspects of constructive logic". Journal of Logic, Language, and Information 6:2, pp. 191-212.

G. Sundholm (1998). "Inference versus Consequence". In T. Childers (ed.), The Logica Yearbook 1997, Prague: Filosofia, pp. 26-36.

G. Sundholm (2001). “A Plea for Logical Atavism”. In O. Majer (ed.), The Logica Yearbook 2000, Prague: Filosofia, pp. 151-162. 
G. Sundholm (2009). "A Century of judgement and Inference: 1837-1936”. In L. Haaparanta (ed.), The Development of Modern Logic, Oxford: Oxford University Press, pp. 263-317.

G. Sundholm (2013a). “Independence Friendly Language is First Order after all?”. Logique et Analyse, in print.

G. Sundholm (2013b). "Inference and Consequence in an Interpeted Language". Talk at the Workshop Proof theory and Philosophy, Groningen, December 3-5, 2013.

W. Tait (1994). "The law of excluded middle and the Axiom of Choice". In A. George (ed.), Mathematics and Mind, New York: Oxford University Press, pp. 45-70.

T. Tulenheimo (2009). "Independence Friendly Logic". In Edward N. Zalta (ed.), The Stanford Encyclopedia of Philosophy, URL http://plato.stanford.edu/entries/logic-if/.

T. Tulenheimo (2011). "On Some Logic Games in Their Philosophical Context". In A. Lecomte and S. Tronçon (eds.), Ludics, Dialogues and Interaction: PRELUDE Project 2006-2009, Revised Selected Papers, Berlin and Heidelberg: Springer, pp. 88-113.

W. Walkoe (1970). “Finite partially ordered quantification”. Journal of symbolic logic, 35, pp. 535-555.

J. Väänänen (2001). "Second-Order Logic and Foundations of Mathematics". Bulletin of Symbolic Logic, 7, pp. 504-520.

J. Van Benthem (1996). Exploring Logical Dynamics. Stanford/Cambridge: CSLI Publications and Cambridge University Press.

J. Van Benthem (2001). "Correspondence Theory". In D. Gabbay and F. Guenthner (eds.), Handbook of Philosophical Logic, Volume 2, Dordrecht: Reidel, pp. 167-247, 1984. Reprint with addenda in second edition, pp. 325-408.

J. Van Benthem (2011). Logical Dynamics of Information and Interaction. Cambridge: Cambridge University Press.

J. Van Benthem (2014).Logic in Games. Cambridge-Massachusetts: MIT.

H. Van Ditmarsch, W. van der Hoek, and B. Kooi (2007). Dynamic Epistemic Logic. Berlin: Springer. 